\title{
Dissecting the fornix in basic memory processes and neuropsychiatric disease: A review
}

Susan L. Benear, Chi T. Ngo \& Ingrid R. Olson

Temple University, Philadelphia, PA 19122

Address correspondence to:

\author{
Ingrid R. Olson \\ E-mail: iolson@temple.edu \\ Department of Psychology \\ $\mathrm{T}:(215)$ 204-7318 \\ Temple University \\ F: (215) 204- 5539 \\ 1701 N. $13^{\text {th }}$ Street \\ Philadelphia, PA 19122
}

Number of words in abstract: 169

Number of tables, figures: 3 tables and 4 figures

Keywords: fornix, white matter, episodic memory, hippocampus, diffusion tensor imaging, Alzheimer's Disease, epilepsy, acetylcholine, theta, obesity, nucleus accumbens, deep brain stimulation, schizophrenia, stress, bipolar disorder, mood 
The fornix is the primary axonal tract of the hippocampus, connecting it to modulatory subcortical structures. This review reveals that fornix damage causes cognitive deficits that closely mirror those resulting from hippocampal lesions. In rodents and non-human primates, this is demonstrated by deficits in conditioning, reversal learning, and navigation. In humans, this manifests as anterograde amnesia. The fornix is essential for memory formation because it serves as the conduit for theta rhythms and acetylcholine, as well as providing mnemonic representations to deep brain structures that guide motivated behavior, such as when and where to eat. Diffusion imaging research is revealing that the fornix plays a key role in mild cognitive impairment and Alzheimer's Disease, and can potentially predict conversion from the former to the latter. Emerging imaging findings link perturbations in this structure to schizophrenia, mood disorders, and eating disorders, although more research is needed. Cutting-edge research is currently investigating how deep brain stimulation of the fornix can potentially halt memory loss, control epileptic seizures, and even improve mood. 


\section{Introduction}

Seminal work showing that bilateral damage to the hippocampus causes anterograde amnesia (Milner \& Scoville, 1957) focused the lens of episodic memory research on the hippocampus, often to the exclusion of other connected brain regions. However, anterograde amnesia can arise from focal damage to other parts of the brain. For instance, prolonged deficiencies in thiamine can cause diencephalic amnesia, which is associated with destruction of the mammillary bodies and/or portions of the thalamus (Gudden, 1896). Anterograde amnesia can also appear after discrete lesions to the basal forebrain (Abe, Inokawa, Kashiwagi, \& Yanagihara, 1998). All of these brain regions are linked together by a C-shaped white matter pathway called the fornix. Importantly, fornix damage alone can cause severe and unremitting anterograde amnesia.

However, fornix damage in humans is exceedingly rare. Until recently, it was difficult to know whether the wealth of findings about the fornix from rodents and non-human primates extended to humans. We can now use non-invasive imaging techniques (e.g. diffusion weighted imaging (DWI)) to gain insight into the functional properties, as well as pathological processes, that are associated with various white matter tracts. The goal of this review is to provide a detailed review of the functions and processes supported by the fornix to help researchers interpret their results and plan hypothesis driven DWI research. To achieve this goal, we describe the anatomy of this tract and detail the effects of fornix lesions on memory and other cognitive domains in both humans and animals. In addition, we review the small diffusion imaging literature, discuss the potential information transmission properties of this white matter tract in episodic memory, and point out future directions.

\section{Anatomy of the fornix}

The fornix, illustrated in Figure 1, constitutes the primary efferent and afferent pathway of the hippocampus and is a central component of the Papez Circuit (Amaral \& Lavenex, 2007). As an efferent pathway, the fornix begins as the fimbria, the attached white matter of the hippocampus, then becomes a detached bundle, forming the fornical crus. The two crura join beneath the splenium of the corpus collosum to form the body of the fornix (Catani, Howard, Pajevic, \& Jones, 2002; Douet \& Chang, 2015). These fibers descend into the forebrain to become the columns of the fornix, which split around the anterior commissure. The columns then split further into the pre-commissural fibers - which innervate the septal nuclei, diagonal band of Broca, and the nucleus accumbens - and the post-commissural fibers - which extend to the mammillary bodies of the diencephalon. The post-commissural fibers divide into two smaller bundles - one that innervates several anterior hypothalamic areas, and one that carries fibers to the anterior thalamic nuclei (Amaral \& Lavenex, 2007). The fornix is bidirectional-it also contains fibers leading from these subcortical regions to the hippocampus. Most external modulators of the products of hippocampal processing - namely the septal nuclei/diagonal band of Broca, locus coeruleus, and raphe nuclei (the latter two regions synapse onto the septal nuclei before progressing to the hippocampus) - enter the hippocampal formation via the fornix (Amaral \& Lavenex, 2007). Although some papers state that the hippocampus projects to the medial prefrontal cortex (mPFC) via the fornix, this is inaccurate. There is a separate white matter tract that projects from CA1 and the subiculum to the MPFC that passes through the fornix (Parent, Wang, Su, Netoff, \& Yuan, 2010; Godsil, Kiss, Spedding, \& Jay, 2013). 


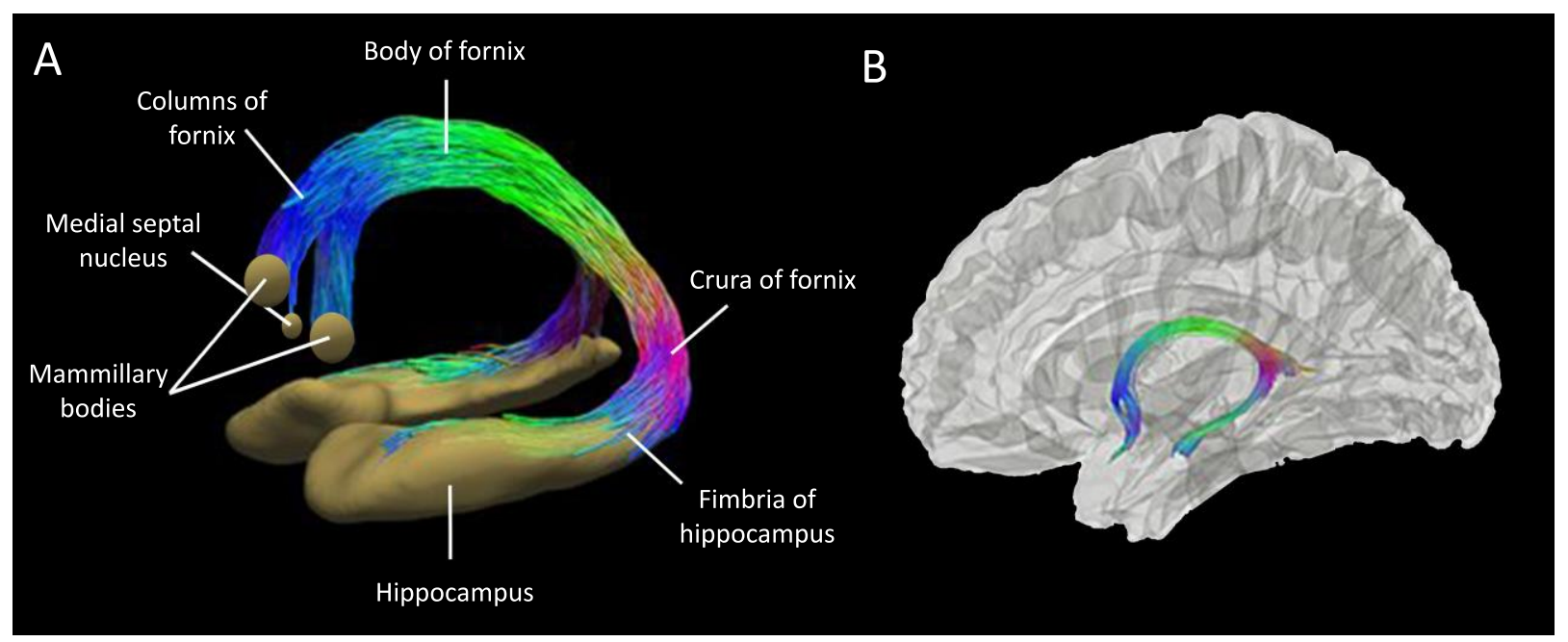

Figure 1. Anatomy of the human fornix. (A) A schematic depiction of the fornix connecting the hippocampus to other subcortical regions. Reproduced and adapted with permission from Shi $\&$ Toga, 2017. (B) The fornix reconstructed using diffusion-weighted imaging techniques in a human. Reproduced with permission from Yeh et al., 2018.

\section{Putative functions of the fornix}

\subsection{Episodic memory}

The literature on the fornix consistently and overwhelmingly links it to long-term forms of memory. In the following sections, we review the relevant literature on non-human animals and humans.

\subsubsection{Lesions of the fornix in non-human animals}

There is a long history of creating lesions in the fornix of rodents and non-human primates to investigate the causal role of the fornix in long-term forms of memory. In these studies, animals are first trained on a task to a learning criterion, after which they undergo a surgical procedure to sever the fornix, while leaving the hippocampal formation intact. After a period of recovery, the animals are sometimes retested on the previously-learned task to test for retrograde amnesia. They are then taught a new task, after which they are tested to determine whether they were able to acquire new learning, or if they are inhibited by anterograde amnesia. The memory tasks used in non-human primates and rodents are generally spatial or navigational in nature, although some are simply visual recognition tasks. Spatial and navigational tasks require the encoding and retrieval of spatiotemporal context and therefore, serve as a proxy for episodic memory.

Do fornix lesions in non-human animals cause deficits on traditional "hippocampallydependent" tasks? A rich intellectual history links trace conditioning, contextual fear conditioning, reversal learning, and spatial tasks to hippocampal processing. Performance on all of these tasks is severely affected by lesions to the fornix (detailed in Table 1). For instance, one study found that fornix lesions disrupted rabbits' ability to learn the CS-US association when there was a delay in a trace conditioning paradigm (Oswald, Maddox, \& Powell, 2007). Another study used a contextual fear conditioning paradigm and found that rats with fornix lesions do not exhibit freezing behavior upon being returned to the cage in which the CS and US were initially paired (Phillips \& LeDoux, 1995; Maren \& Fanselow, 1997) nor they do exhibit contextdependent freezing behavior that was previously extinguished (Ji \& Maren, 2008). Animals with 
fornix transections can learn simple associations when they are repeated many times, but struggle to learn the reversal or reassignments, taking far longer to reach criterion than control animals (Hirsch \& Segal, 1972; Wiig, Cooper, \& Bear 1996; Wilson et al., 2007). The largest literature of all shows that fornix transection consistently leads to robust impairments in learning new routes and spatial locations, both in non-human primates (Murray, Davidson, Gaffan, Olton, \& Suomi, 1989; Kwok \& Buckley, 2006) and in rodents (Hirsh \& Segal, 1972; O’Keefe, Nadel, Keightley, \& Kill, 1975; Walker \& Olton, 1979; Ennaceur \& Aggleton, 1997; Whishaw \& Tomie, 1997; De Bruin, Moita, De Brabander, \& Joosten, 2001); see Figure 2.

\section{T-Maze Alternation in Rodents}

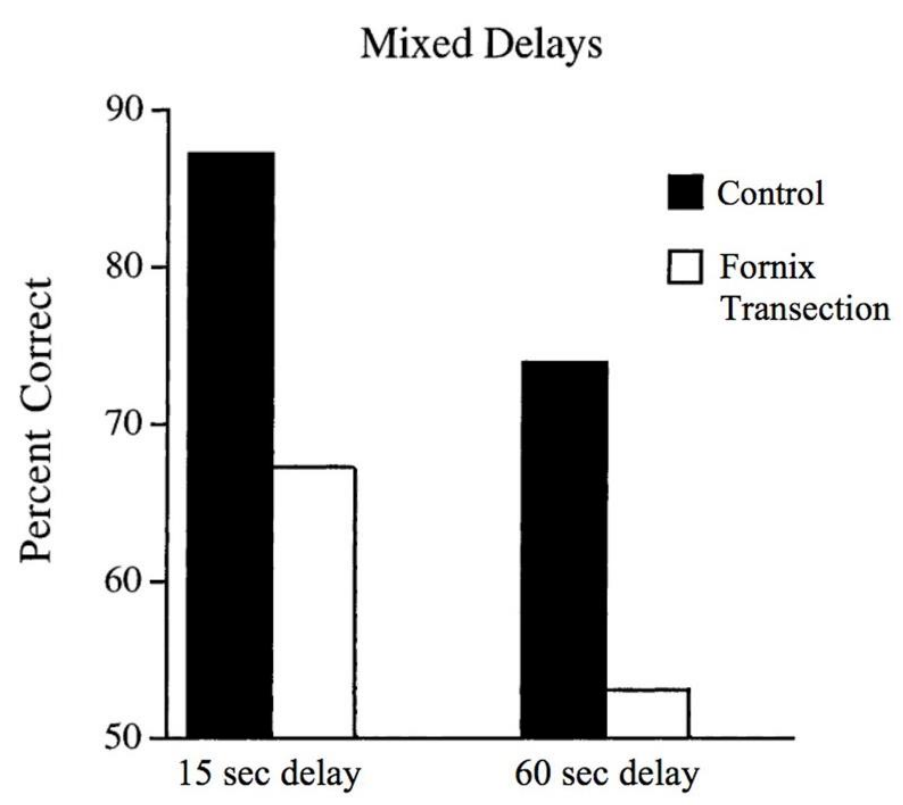

Figure 2. The effect of fornix transection on navigation in non-human primates. Compared to controls, rodents with fornix lesions perform significantly worse on navigational tasks at various delays. Reproduced with permission from Bussey et al., 2000.

Crucially, there is robust evidence that fornix lesions do not lead to deficits in non-spatial memory tasks such as object recognition in animals (Markowska, Olton, Murray, \& Gaffan, 1989; Gaffan, 1992; Ennaceur, Neave, \& Aggleton, 1996; Ennaceur \& Aggleton, 1997; Bussey et al., 2000; Wilson et al., 2007). Simple object recognition is thought to be subserved by the perirhinal cortex rather than the hippocampus, however, there is some evidence to the contrary (Bachevalier et al., 1985; Gaffan, 1994; Browning, Gaffan, Croxson, \& Baxter, 2010), although the authors in these cases admit to "small and unreliable" effects, or use complex stimuli more akin to "scenes" than objects. Generally, simple object recognition is not impaired by fornix lesions, but once a spatial or contextual component is added to the task, there are consistent and robust deficits in performance.

\subsubsection{Lesions of the human fornix}

Humans rarely incur damage to the fornix. When it does occur, it is typically in the context of a colloid cyst of the third ventricle (Gaffan, Gaffan, \& Hodges, 1991; Hodges \& Carpenter, 1991; Poreh et al., 2006; Tsivilis et al., 2008) or some other midline tumor. There are 
also rare reports of fornix-specific damage resulting from strokes (Moudgil, Azzouz, Al-Azzaz, Haut, \& Gutmann, 2000; Park, Hahn, Kim, Na, \& Huh, 2000) or traumatic brain injury (D'Esposito, Verfaellie, Alexander, \& Katz, 1995). Findings from this small clinical literature have documented that fornix lesions give rise to a persistent anterograde amnesia best described as a disconnection syndrome (see Table 1). This memory deficit occurs against the backdrop of intact intellect and the absence of anosognosia. Working memory, procedural memory, executive and language functioning (except for slightly reduced verbal IQ; Hodges \& Carpenter, 1991; Park et al., 2000) are generally in the normal range. When the fornix is completely transected, memory deficits are stimulus invariant, such that they are observed for all types of visual and verbal materials. Even partial damage results in severe decrements, especially if insult is incurred to the left fornix, given the lateralization of language abilities and the import of language to adequate functioning. There is some material specificity in the expected direction, with left fornix damage tending to lead to verbal memory deficits and right fornix damage being more associated with visual memory deficits (Gaffan et al., 1991; McMackin, Cockburn, Anslow, \& Gaffan, 1995). However, it is worth noting that the extent of damage is more predictive of deficits than the lesion location on both verbal and visual tasks (Korematsu, Hori, Morioka, \& Kuratsu, 2010; Sara, Dyon-Laurent, Guibert, \& Leviel, 2004 for an animal model).

The episodic memory deficits are generally more profound for recall than for recognition (Calabrese, Markowitsch, Harders, Scholz, \& Gehlen, 1995; Tsivilis et al., 2008), although there are deficits in recognition memory as well (Calabrese et al., 1995; D'Esposito et al., 1995; Gaffan, et al., 1991). The clinical profile does not typically include confabulation, distinguishing this form of amnesia from the diencephalic variant. Nevertheless, the episodic memory deficits following fornix lesions in humans are profound, unremitting, and bear an uncanny resemblance to the episodic memory deficits observed after focal bilateral hippocampal lesions.

The multi-trace theory of memory proposes that retrieving past experiences, even remote ones from childhood, necessitates the involvement of the hippocampus (Nadel, Samsonovich, Ryan, \& Moscovitch, 2000). Interestingly, there is some evidence that fornix damage causes problems recollecting the far past - deficits in recalling pre-operative learning in animals (Wiig et al., 1996; Squire, Clark, \& Knowlton, 2001; Winocur, McDonald, \& Moscovitch, 2001) as well as retrograde amnesia in humans (Hodges \& Carpenter, 1991; D'Esposito et al., 1995; Poreh et al., 2006). We note that few studies have tested this in humans, but those that have examined it have reported that the retrograde amnesia is primarily for episodic aspects of remote memory, not semantic aspects of remote memory - thus, it is most commonly observed in autobiographical recollection (Hodges \& Carpenter, 1991; Poreh et al., 2006). However, other studies find normal levels of pre-operative memory in animals (Gaffan, Parker, \& Easton 2001; Buckley et al., 2004; Buckley, Wilson, \& Gaffan 2008) or no retrograde amnesia in humans (Park et al., 2000). In sum, the role of the fornix in accessing remote memories is underdeveloped, but potentially quite interesting.

\subsubsection{Diffusion-weighted imaging in humans}

Lesion evidence provides strong inferential power about a region's function. However, because fornix lesions are so rare in humans, other means must be sought after to elucidate the role of the fornix in cognitive function. Diffusion-weighted imaging (DWI) can be used to examine how the fornix relates to memory and cognition. This technique uses Brownian motion to create contrast in magnetic resonance imaging (MRI) images - in other words, it tracks the rate and direction that water molecules move in the brain. There are several indices of water 
diffusivity, with two of the most commonly used being fractional anisotropy (FA) and mean diffusivity (MD). The interpretation of these indices is not always straightforward, and there is not a one-to-one correspondence between any measure and any particular characteristic of white matter. FA is a composite measure of the degree of anisotropy-asymmetry of water movement - in a given voxel, and ranges from 0 (totally isotropic) to 1 (totally anisotropic). It is taken to indicate the degree of directional restriction of water diffusivity within a voxel. MD on the other hand is a measure overall diffusivity (mean of three eigenvalues of the diffusion tensor) in a given voxel, with lower values indicating less diffusivity.

Much of the fornix is located in the third ventricle, inferior (and perpendicular) to the corpus callosum, and, as such, is completely surrounded by cerebrospinal fluid (CSF). This location makes the fornix particularly difficult to image due to ever-present susceptibility artifacts (Sullivan, Rohlfing, \& Pfefferbaum, 2010; Gunbey et al. 2014; Hodgetts et al., 2017, 2018). We discuss this issue and potential solutions in Box 1.

\section{Box 1. How to measure the fornix with diffusion weighted imaging}

There are several issues that make it difficult to measure the fornix noninvasively. The fornix is small relative to voxel size and it is highly curved, which makes it difficult to reconstruct in DWI. Most importantly, it is difficult to accurately measure due to its location in the third ventricle. Because the diffusion properties of CSF differ greatly from that of white matter-namely, that diffusion is completely free in CSF - this can strongly interfere with the ability to get accurate diffusion measures in the fornix. This can result from inclusion of CSF in many of the voxels identified as part of the fornix, and from pulsatile motion in the CSF surrounding fornical voxels (Sullivan et al., 2010; Gunbey et al., 2014; Hodgetts et al., 2017, 2018). It is therefore paramount that researchers account for this in their analyses that involve the fornix.

Kaufmann and colleagues (2017) proposed the following strategies for CSF remediation. During acquisition, fluid-attenuated inversion recovery prepulses can be used (Cheng, Chung, Chen, \& Chou, 2011). Alternatively, during analysis, ventricular volume can be regressed out and free-water elimination can be used (Pasternak, Sochen, Gur, Intrator, \& Assaf, 2009). It is essential to consider these strategies when conducting a between-subject design, since ventricular alterations may correlate with age or disease state of one of your populations, thereby biasing your results. For instance, it is known that neurologically normal older adults have relatively larger ventricles than younger adults (Apostolova et al., 2012). In addition, individuals with MCI and AD (Apostolova et al., 2012), multiple sclerosis (Dalton et al., 2006), and schizophrenia (Sayo, Jennings, \& Van Horn, 2012) commonly have ventricular enlargement relative to age-matched controls.

It is also difficult to measure the fornix noninvasively because many automated diffusion imaging toolboxes such as AFQ and TRACULA do not include this structure. The majority of published studies on the fornix have used an FSL package called tract-based spatial statistics (TBSS), which is appropriate for some, but not all analyses, and has known pitfalls (Bach et al., 2014). Manual drawing methods can be difficult to reproduce across subjects and laboratories and are time consuming to conduct. A few studies have successfully employed probabilistic fiber tracking techniques using seed, waypoint, and target masks to reconstruct the fornix (Bennett, Huffman, \& Stark, 2015; Ngo et al., 2017). Our laboratory uses this method. 

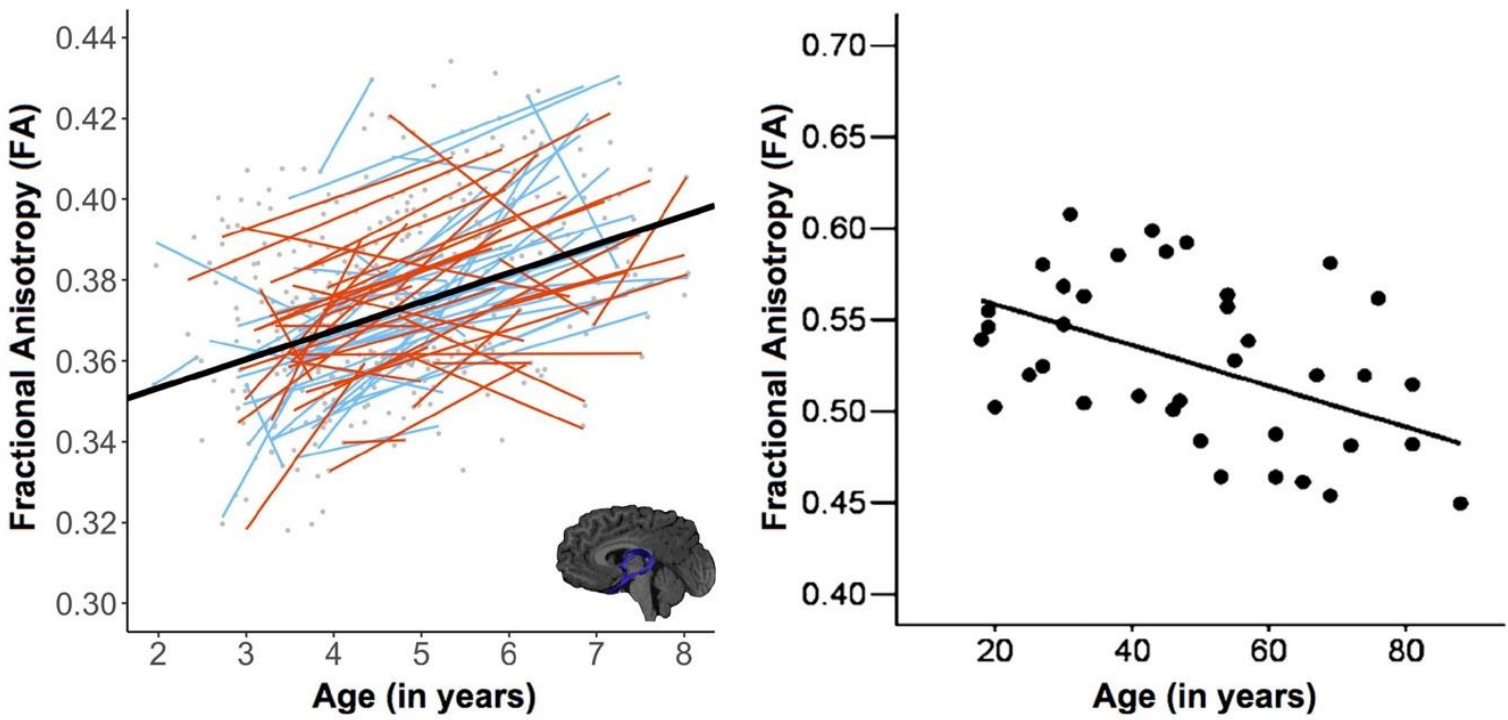

Figure 3. Fornix microstructure in development and aging. (A) In early childhood, fractional anisotropy increases with age in both boys (in blue) and girls (in red). Reproduced with permission from Reynolds et al., Jan. 2019 [Preprint]. (B) Increasing age is correlated with decreasing fractional anisotropy in the fornix. Reproduced with permission from Stadlbauer et al., 2008 .

A small literature describes the development of the fornix and the relationship of DWI metrics to memory performance. While it has been shown that fornix macrostructure is established by the time a human fetus reaches 19 gestational weeks (Huang, 2010), it is less clear when the microstructure reaches maturity. When looking at children beginning at age 2, 
researchers found a relationship between age and increased FA in the fornix (Reynolds, Grohs, Dewey, \& Lebel, Jan 2019 [Preprint]), suggesting that fornix microstructure is still developing in these very young children (see Figure 3). However, no relationship between age and fornix FA was found in studies of children in which the youngest participants were 4 years old (Ngo et al., 2017), 5.6 years old (Lebel, Walker, Leemans, Phillips, \& Beaulieu, 2008) and 7 years old (Wendelken et al., 2015), which suggests that fornix microstructure reaches maturity before age 4. Relationships between age and fornix MD during development are conflicting, with some evidence suggesting decreased MD in the fornix in children with increasing age (Lebel et al., 2008), whereas other studies show no relationship between age and MD (Reynolds et al., 2019). This discrepancy could be due to the different age ranges and developmental stages of children included in these studies. Wendelken and colleagues (2015) also found a relationship between fornix FA and memory performance in adults, but not in children. This finding is surprising but potentially explained by issues surrounding imaging of the fornix (see Box 1).

\subsubsection{DWI of the fornix in adult episodic memory}

Consistent with lesion findings, the small diffusion imaging literature in healthy young adults has consistently reported that lower fornix FA and/or higher MD correlates with worse episodic memory performance (Rudebeck et al., 2009; Hodgetts et al., 2017, 2018). These findings suggest that episodic memory impairments that accompany old age should be associated with decreased FA/increased MD.

Indeed, a highly reliable finding in the DWI literature is that in healthy populations of older adults, advanced age is associated with decreased FA and/or increased MD values (Zahr, Rohlfing, Pfefferbaum, \& Sullivan, 2009; Bennett et al., 2015; Bennett \& Stark, 2016; Gunbey et al., 2014; Jang, Cho, \& Chang, 2011; Metzler-Baddeley, Jones, Aggleton, \& O'Sullivan, 2011; Metzler-Baddeley, O’Sullivan, Belaroussi, Aggleton, \& Jones, 2011; Pelletier et al., 2013; Stadlbauer, Salomonowitz, Strunk, Hammen, \& Ganstlandt, 2008; Zhuang et al., 2012, 2013) in the fornix (see Figure 3). A few studies do not find a relationship between increasing age and fornix FA/MD (Doxey \& Kirwan, 2015; Kantarci et al., 2011; Rémy, Vayssière, Saint-Aubert, Barbeau, \& Pariente, 2015; Metzler-Baddeley et al., 2011b), potentially due to a failure in accounting for age-related differences in ventricular volume/CSF around the fornix (see Box 1).

Importantly, the observed decreases in FA correlate with reduced episodic memory performance in older adults (Antonenko et al., 2016; Bennett et al., 2015; Bennet \& Stark, 2016; Kantarci et al., 2014; Metzler-Baddeley et al., 2011a \& 2011b; Ray et al, 2015; Zhuang et al., 2013), as do increases in MD (Antonenko et al., 2016; Bennett et al., 2015; Zhuang et al., 2013). There are also reduced fornix fiber counts with increasing age (Stadlbauer et al, 2008), and there is some evidence, albeit from a small sample, that higher fornix FA in older adults is related to better performance on measures of working memory and motor control (Zahr et al., 2009).

Only a few studies have looked at multiple within-subject's measures of diffusion. Among those that have was a study by Antonenko and colleagues (2016) that trained a group of healthy older adults on an object-location paradigm, a spatial task designed to index episodic memory. The researchers found increased FA and decreased MD in the fornix from pre- to posttraining. They also found that increased FA across training was related to better recall—but not recognition - performance at post-test (Antonenko et al., 2016).

\subsubsection{Summary of findings on episodic memory}


Findings from the reviewed studies consistently and overwhelmingly converge on the idea that the fornix is essential for memory tasks that are traditionally thought of as "hippocampal." Fornix damage in rodents or monkeys causes deficits across a range of tasks including trace conditioning, contextual fear conditioning, spatial navigation, object-location pairing, and other visuospatial tasks. Moreover, fornix lesions in non-human primates mirror the temporality that is observed in humans suffering from bilateral hippocampus lesionsanterograde but limited retrograde amnesia after transection of the fornix, evidenced by the primates' accurate recall of pre-operative memories/experiences in many studies, but inability to form new memories of tasks learned post-operatively (Buckley, Charles, Browning, \& Gaffan, 2004; Buckley, Wilson, \& Gaffan, 2008; Gaffan et al., 2001). In humans, fornix damage causes anterograde amnesia that is worse for recollection as compared to recognition. The clinical profile is more similar to medial temporal lobe amnesia than it is to diencephalic, due to the absence of confabulation. Are the deficits after fornix lesions of the same duration and of the same magnitude as that observed after hippocampal lesions in non-human animals? Most studies suggest that the deficits are virtually identical (e.g. Aggleton, Keith, Rawlins, Hunt, \& Sahgal, 1992; Maren \& Fanselow, 1997). Recent findings using non-invasive methods to examine the fornix - DWI - converge on a similar narrative, showing a correlation between diffusion metrics and episodic memory performance across a range of age groups and tasks.

\subsection{Spatial cognition, writ large}

A second putative role for the fornix in cognition is that it plays a key role in spatial memory and spatial perception. This view stems from a controversial model that proposes that the hippocampus plays a material specific role in cognition: that it is essential for perceiving and remembering scenes and locations, while another medial temporal lobe region - the perirhinal cortex - plays an essential role in face/object perception (reviewed in Graham, Barense, \& Lee, 2010). Because the fornix innervates the hippocampus, but not perirhinal cortex, these findings would suggest that fornix transection should cause spatial memory and perception deficits, but not object/face memory and perception deficits. Supporting this view, the literature shows that in non-human primates, memory for objects and faces is usually spared, while spatial memory is impaired, after fornix transection (Markowska et al., 1989; Gaffan, 1992; Ennaceur, Neave, \& Aggleton, 1996; Ennaceur \& Aggleton, 1997; Bussey, Duck, Muir, \& Aggleton, 2000; Wilson, Baxter, Easton, \& Gaffan, 2007; Browning et al., 2010; Kwok \& Buckley, 2009; Browning et al., 2010; Kwok \& Buckley, 2010; but see Bachevalier, Parkinson, \& Mishkin, 1985; Gaffan, 1994). In addition, Graham and colleagues used DWI in young healthy participants and found that higher fornix FA was related to better performance on spatial memory measures but did not relate to performance on object memory measures (Hodgetts et al., 2017, 2018; Rudebeck et al., 2009).

As compelling as these findings are, it must be remembered that humans differ from rats and monkeys in several small ways, but also in one major way: we have language. Language, much like flight, is a species game-changer. The ability to remember someone's name, to communicate instructions, or to follow the narrative of a story is essential for human interactions. And humans with fornix damage fail to remember words and conversations, consistent with a global amnesia (Calabrese et al., 1995; D’Esposito et al., 1995). A quick look at Table 1 shows that nearly every study of individuals with fornix damage reported verbal memory impairments. Thus, evidence from humans does not support the claim that the fornix is only involved in spatial memory. 
As for the claim regarding the role of the fornix in visual perception, there is evidence from non-human primates that fornix transection impairs the ability to discriminate between pictures of complex scenes, while leaving the ability to discriminate between pictures of objects intact (Gaffan, 1992 \& 1994; Easton, Ridley, Baker, \& Gaffan, 2002; Wilson et al., 2008; Browning et al., 2010). The tiny literature from humans with fornix lesions is mixed (Gaffan et al., 1991; D'Esposito et al., 1995) while the only DWI study found evidence for the material specific role such that fornix microstructure correlated with the perception of scenes (Postans et al., 2014). To summarize, the literature linking the fornix to spatial perception is small and findings are mixed, and potentially confounded by transaccadic memory. Future research should investigate this issue in more detail.

\subsection{Working memory, curiosity, and other aspects of cognition}

Some researchers have conducted diffusion imaging studies on healthy participants and found associations between working memory performance and higher FA (Zahr et al., 2009) and lower longitudinal and transverse diffusivity in the fornix (measures similar to MD; Sullivan et al., 2010). However, studies of patients with fornix lesions find that they have normal working memory abilities (Calabrese et al., 1995; Gaffan et al., 1991; Hodges \& Carpenter, 1991; Park et al., 2000; Poreh et al., 2006; Tsivilis et al., 2008). One case report detailed a patient with deficits in working memory, but this patient sustained a gunshot wound, and the authors speculate her working memory deficit was a result of damage by the bullet to the left posterior parietal region (D’Esposito et al., 1995). In sum, evidence for the fornix playing an essential role in working memory is weak.

Recently, a DWI study linked variation in fornix microstructure to the traits of novelty seeking and curiosity (Valji et al., May 2019 [Preprint]). These findings make sense in light of a large literature showing that the hippocampus is extremely sensitive to novelty, containing a comparator mechanism that allows incoming information to be compared to stored representations (Lisman \& Grace, 2005).

Other aspects of cognition - reasoning, attention, language, mathematical abilities, and conceptual knowledge, for instance - do not appear to rely on the fornix, although, admittedly, this has not been an area of interest by researchers studying the fornix.

\section{Table 1: The relationship between the fornix and cognitive performance.}

\begin{tabular}{|l|l|l|}
\hline \multicolumn{1}{|c}{ Tasks } & \multicolumn{1}{c|}{ Summary of Findings } & \multicolumn{1}{c|}{ References } \\
\hline $\begin{array}{l}\text { Trace and } \\
\text { Contextual Fear } \\
\text { Conditioning }\end{array}$ & $\begin{array}{l}\text { - Reliable deficits across } \\
\text { tasks and non-human } \\
\text { species. } \\
\text { - No studies in humans. }\end{array}$ & $\begin{array}{l}\text { Phillips \& LeDoux, 1995; Maren \& Fanselow, } \\
\text { 1997; Oswald et al., 2007; Ji \& Maren, 2008 }\end{array}$ \\
\hline Reversal Learning & $\begin{array}{l}\text { - Reliable deficits across } \\
\text { tasks and non-human } \\
\text { species. } \\
\text { - No studies in humans. }\end{array}$ & $\begin{array}{l}\text { Hirsch \& Segal, 1972; Wiig et al., 1996; Wilson } \\
\text { et al., 2007 }\end{array}$ \\
\hline
\end{tabular}




\begin{tabular}{|c|c|c|}
\hline $\begin{array}{l}\text { Spatial Memory } \\
\text { and Spatial } \\
\text { Navigation }\end{array}$ & $\begin{array}{l}\text { - Reliable deficits across } \\
\text { tasks and species. } \\
\text { - Reliable relationship } \\
\text { between performance on } \\
\text { spatial tasks and fornix } \\
\text { DWI parameters in } \\
\text { humans. }\end{array}$ & $\begin{array}{l}\text { Hirsch \& Segal, 1972; O’Keefe et al., 1975; } \\
\text { Walker \& Olton, 1979; Markowska et al., 1989; } \\
\text { Murray et al., 1989; Aggleton et al., 1992; } \\
\text { Gaffan, 1994; Ennaceur et al., 1996; Ennaceur \& } \\
\text { Aggleton, 1997; Parker \& Gaffan, 1997; } \\
\text { Whishaw \& Tomie, 1997; Bussey et al., 2000; } \\
\text { De Bruin et al., 2001; Easton et al., 2002; } \\
\text { Buckley et al., 2004 and 2008; Kwok, 2006; } \\
\text { Kwok \& Buckley, 2010; Kwok et al., 2015; } \\
\text { Hodgetts et al., 2017, } 2018\end{array}$ \\
\hline $\begin{array}{l}\text { Traditional } \\
\text { Episodic Memory } \\
\text { Tasks, e.g. WMS, } \\
\text { CVLT, etc. }\end{array}$ & $\begin{array}{l}\text { - Reliable anterograde } \\
\text { amnesia for all materials } \\
\text { after fornix damage. } \\
\text { - Correlational evidence } \\
\text { from similar tasks using } \\
\text { DWI. }\end{array}$ & $\begin{array}{l}\text { Gaffan, Gaffan, \& Hodges, 1991; Hodges \& } \\
\text { Carpenter, 1991; D’Esposito et al., 1995; } \\
\text { Mougdil et al., 2000; Park et al., 2000; Poreh et } \\
\text { al., 2006; Tsivilis et al., 2008; Vann et al., 2008; } \\
\text { Rudebeck et al., 2009; Fletcher et al., 2013 \& } \\
\text { 2014; Hodgetts et al., } 2017 \text { \& Aug. } 2019\end{array}$ \\
\hline $\begin{array}{l}\text { Remote episodic } \\
\text { memory/autobiogra } \\
\text { phical memory }\end{array}$ & $\begin{array}{l}\text { - Intact memory for pre- } \\
\text { operative learning in } \\
\text { non-human primates. } \\
\text { - Emerging evidence for } \\
\text { link between the fornix } \\
\text { and remote episodic, but } \\
\text { not semantic, memory in } \\
\text { humans. }\end{array}$ & $\begin{array}{l}\text { Hodges \& Carpenter, 1991; Gaffan et al., 2001; } \\
\text { Buckley et al., 2004; Poreh et al., 2006; Gilboa et } \\
\text { al. 2006; Buckley et al., 2008; Vann et al., 2008; } \\
\text { Hodgetts et al., } 2017\end{array}$ \\
\hline $\begin{array}{l}\text { Object and Scene } \\
\text { Perception/Recogni } \\
\text { tion Tasks: } \\
\text { (delayed)-(non)- } \\
\text { matching-to- } \\
\text { sample, } \\
\text { spontaneous object } \\
\text { recognition, object } \\
\text { face, or scene } \\
\text { discrimination }\end{array}$ & $\begin{array}{l}\text { - Mixed findings. Fornix } \\
\text { transection does not } \\
\text { produce an impairment } \\
\text { in simple object } \\
\text { perception or recognition } \\
\text { tasks. } \\
\text { - Emerging evidence that } \\
\text { the fornix is implicated } \\
\text { in some types of } \\
\text { complex visuospatial } \\
\text { processing. }\end{array}$ & $\begin{array}{l}\text { Deficits: Bachevalier et al., 1985; Gaffan, 1994; } \\
\text { Easton et al., 2002; Wilson et al., 2008; } \\
\text { Browning et al., 2010. } \\
\text { No deficits: Markowska et al. 1989; Gaffan et al., } \\
\text { 1991; Gaffan 1992; D’Esposito et al., 1995; } \\
\text { Ennaceur, Neave, \& Aggleton, 1996; Ennaceur \& } \\
\text { Aggleton, 1997; Bussey et al., 2000; Wilson et } \\
\text { al., 2007; Rudebeck et al., 2009; Kantarci et al. } \\
\text { 2011; Postans et al., } 2014\end{array}$ \\
\hline
\end{tabular}

\section{Mechanistic role of the fornix}

The reviewed empirical literature strongly indicates that the fornix plays an essential role in episodic forms of memory. Here we ask what is the mechanistic role of the fornix? Rigorous investigations in rodents have identified several types of information transmitted through the fornix, reviewed next.

\subsection{Transmission from basal forebrain to the hippocampus}

A key role of the fornix is to transmit an essential neurotransmitter-acetylcholine-from the basal forebrain to the hippocampus. The medial septum (a region in the basal forebrain, 
which in turn receives input from the hypothalamus and several brainstem areas (Khakpai, Nasehi, Haeri-Rohani, Eidi, \& Zarrindast, 2013) is the brain's primary source for acetylcholine, which is transmitted to the frontal lobe, as well as to the hippocampus via the fornix. Damage or deterioration of the fornix harms acetylcholine delivery to the hippocampus (Rawlins, Feldon, \& Gray, 1979; Blaker, Armstrong, \& Gage, 1988). We know that acetylcholine plays an essential role in memory based on findings showing that depletion of basal forebrain acetylcholine precedes Alzheimer's Dementia (Muir, 1997), that blocking acetylcholine in rodents with scopolamine inhibits episodic memory formation (Dixon, Bao, Long, \& Hayes, 1996), and that supplementing acetylcholine can improve episodic memory (Oswald et al., 2007). It is believed that the mechanistic role of acetylcholine in the hippocampus is to up-regulate memory encoding while simultaneously down-regulating memory consolidation (Hasselmo, 1999). In other words, acetylcholine acts like a switch, allowing the hippocampus to shift to different functional phases. This suggests that organisms with fornix damage would show improved memory encoding (but not consolidation) when taking supplemental acetylcholine (for one example of this, see Oswald et al., 2007). It is thus possible that the observed memory impairments after fornix damage can be completely explained by harkening to essential neurotransmitter depletion. However, there is an orthogonal explanation regarding theta rhythms.

Theta rhythms are found throughout the brain and dominate the local field potential in the hippocampus. There is mounting evidence that hippocampal theta rhythm (4-12 Hz) plays an important role in episodic memory (e.g., Hsieh \& Ranganath, 2014) and spatial navigation (Buzsáki, 2005). Theta power at encoding correlates with subsequent word recall (Klimesch, Doppelmayr, Russegger, \& Pachinger, 1996), and memory for word-video associations (Staudigl \& Hanslmayr, 2013). Furthermore, greater theta-band coherence compared to baseline for the MTL-prefrontal cortex interaction was found during memory recall (Anderson, Rajagovindan, Ghacibeh, Meador, \& Ding, 2010). Theta may also play some role in memory bindingremembering the co-occurrence of multiple elements within an event (Buzsaki \& Draguhn, 2004; Hanslmayr, Staresina, \& Bowman, 2016). Corroborating this view, several studies have found that hippocampal theta-gamma coupling is linked to item-context binding processes (Lega, Jacobs, \& Kahana, 2012; Staudigl \& Hanslmayr, 2013; Tort, Komorowski, Manns, Kopell, \& Eichenbaum, 2009; Backus, Schoffelen, Szebényi, Hanslmayr, \& Doeller, 2016). GABAergic neurons in the medial septum serve as generator and pacemaker for theta. These cells burst at theta frequencies in-vivo, and destruction of the medial septum halts whole-brain theta rhythms, while destruction of the fornix halts hippocampal theta rhythms (Rawlins et al., 1979), resulting in episodic memory impairments (Cassel, 1997; Lipponen, Woldemichael, Gurevicius, \& Tanila, 2012). There is also evidence that acetylcholine modulates theta power (Zhang, Lin, \& Nicolelis, 2010).

\subsection{Transmission from the hippocampus to the basal forebrain}

The mechanisms we just described only explain one direction of fornix information flow; it does not explain how hippocampal outflow via the fornix modulates subcortical structures. The literature relevant to this question is surprisingly small. However, a few recent studies suggest that this flow of information may be essential for modulating motivated behavior. For instance, a recent study reported that the hippocampus regulates social attack via a circuit from CA2$>$ lateral septum->ventromedial hypothalamus. It is possible that a decision to engage in social attack requires retrieval of memories of past social encounters that allow a prediction to be made about the possible win-lose outcome of aggressive behavior (Pagani et al., 2015). Using a similar 
logic, we speculate that the hippocampus, via the fornix, also regulates the decision to engage in sexual behavior, based on older findings showing that direct electrical stimulation of the human septum elicited subjective pleasure and sexual arousal (Olds \& Milner, 1954; Heath, 1964; Heath, 1972)

Other studies have reported that a circuit from CA3->lateral septum modulates food intake by regulating learned or emotional aspects of food intake, such as how much time has elapsed since the last meal (Sweeney \& Yang, 2015). This finding harkens to studies showing that individuals with anterograde amnesia are unable to recall recent eating and will consume multiple meals in quick succession (Hebben, Corkin, Eichenbaum, \& Shedlack, 1985; Higgs, Williamson, Rotshtein, \& Humphreys, 2008). It also helps to explain new DWI findings linking fornix microstructure to body mass index (Metzler-Baddeley, Baddeley, Jones, Aggleton, \& O’Sullivan, 2013).

The fornix also provides a direct connection between the hippocampus and the nucleus accumbens and there is evidence that this circuit allows memories of reward-predicting environments to guide where animals look for food (Trouche et al., 2019). Taken together, these findings suggest that the fornix transmits mnemonic information that shapes and guides motivated behaviors. Evidence about this role is only beginning to emerge in the literature. It is entirely possible that the third role is broader than our description; the fornix may transmit mnemonic information that guides decision-making in all shapes and forms.

\subsection{Summary}

The reviewed findings suggest three mechanistic functions of the fornix in episodic memory. One role is in transmitting acetylcholine, which switches the hippocampus from a baseline consolidation state to an encoding state. A second potential role is in transmitting theta, which may serve a binding role in episodic memory. A third role is in transmitting mnemonic information that shapes decisions about where to forage, when to feed, and who to fight.

The reviewed findings and mechanisms allow us to conjecture which brain disorders might be linked to fornix dysfunction. Disorders in which there is a prominent episodic memory component such as $\mathrm{MCI}$ and $\mathrm{AD}$ should show fornix pathology. In addition, there are disorders with subtle, but consistent episodic memory impairments, such as schizophrenia and major depression, which may involve the fornix (along with other white matter tracts). Last, disorders linked to aberrant reward seeking behavior, such as obesity or substance abuse, may involve the fornix. These disorders are reviewed next.

\section{Clinical Disorders and the Fornix}

The DWI literature linking the fornix to various clinical disorders has been reviewed in some detail recently by Douet and Chang (2015). These authors reviewed studies linking fornix changes to Parkinson's Disease, multiple sclerosis, frontotemporal dementia, and medial temporal lobe epilepsy (see Douet and Chang, 2015). Other authors have reported changes in the fornix in rare disorders like idiopathic normal pressure hydrocephalus (Hattori et al., 2011; Oishi \& Lyketsos, 2014). Most of these literatures are very small and findings tend to be inconsistent. In the following sections, we review larger literatures linking changes in the fornix to mild cognitive impairment (MCI), Alzheimer's Disease, schizophrenia and psychosis, mood disorders, and eating disorders.

\subsection{The fornix in Mild Cognitive Impairment (MCI)}


Mild Cognitive Impairment (MCI) is a term used to conceptualize the cognitive abilities of older adults whose mental faculties are compromised beyond what would be expected in normal aging. It can be divided into two subtypes: non-amnestic (naMCI) and amnestic (aMCI), with the latter including a memory impairment that exceeds what would be expected in typical aging, but that does not reach the level of dementia (reviewed in Yu, Lam, \& Lee, 2017). Diffusion-weighted imaging is particularly useful for examining changes in the early stages of cognitive impairment, as it is sensitive to subtle white matter alterations that would not be evident using traditional MRI (Moseley, 2002). Of particular relevance to pathology of the fornix is the amnestic variant of MCI, as the memory impairments specific to aMCI should be related to fornix microstructural changes.

Individuals with amnestic MCI have relatively decreased FA in the fornix compared to healthy controls (Kantarci et al., 2014; Zhuang et al., 2012, 2013; Bozoki, Korolev, Davis, Hoisington, \& Berger, 2012). Changes in fornix FA or MD appear to precede conversion to AD, making this a potent biomarker for pathological memory profile (Fletcher et al., 2013 \& 2014; Zhuang et al., 2013; Yu, Lam, \& Lee, 2017), especially since around 40 percent of patients with aMCI will eventually convert to AD (reviewed in Douet \& Chang, 2015). It has even been proposed that the "fornix sign," a discoloration of the fornix in color-coded FA maps of the fornix, can be used to predict conversion to AD (Oishi, Mielke, Albert, Lyketsos, \& Mori, 2012; see Figure 4). Several findings indicate that white matter alterations in limbic tracts may precede gray matter degeneration in the hippocampus as well as secondary loss of white matter volume due to neuronal loss (Zhuang et al., 2013; Fletcher et al., 2013). Some researchers suggest that using models that incorporate both gray matter volume changes as well as white matter microstructural changes together are optimal for detecting the early signs of MCI (Douaud et al., 2013). Importantly, in a study of older adults with MCI, including fornical crus FA in a logistic regression improved the ability of the model to distinguish aMCI from naMCI participants (Gyebnár et al., 2018), underlining the importance of fornix integrity to the degradation of memory capacity in older adults.

A meta-analysis by J. Yu et al. (2017) indicated that the white matter tracts most consistently linked to aMCI were the fornix, uncinate, and parahippocampal portion of the cingulum bundle. Further, their ROI-based analyses showed a consistent relationship between aMCI and fornix FA, but not MD. The authors note that the inconsistency of free water correction across studies might explain the heterogeneity of results for MD and lack of significant findings for this metric, but also might lead to an overestimation of the association between fornix FA and aMCI pathology (Yu, J., et al., 2017). Indeed, other studies have found the opposite pattern - that increased fornix MD is more strongly associated with MCI pathology than is FA (Nir et al., 2013; Nowrangi et al., 2013; Tang, Dai, Feng, Duan, \& Shan, 2017), while still another found that fornix FA and MD are both effective individual predictors of longitudinal cognitive decline in MCI patients (Mielke et al., 2012). It is worth noting, however, that many of these studies do not distinguish between aMCI and naMCI, which may affect the results, as naMCI participants do not always have the memory impairments associated with AD and fornix degradation.

Although this review is focused on the fornix, it is worth mentioning that it is not the only tract implicated in mnemonic impairment and cognitive decline; many studies have reported relationships between cognitive impairment and white matter microstructure of other white matter tracts, particularly the cingulum (Bozoki et al, 2012; Nir et al., 2013; Nowrangi et al, 2013; Yu, J., et al., 2017; Gyebnár et al., 2018). The literature on MCI indicates that changes in 
the microstructure the fornix as well as the cingulum bundle can be important predictors of memory impairment and of eventual conversion to AD. Future diffusion imaging studies should focus on tracking older adults longitudinally to better elucidate which diffusion measures are most sensitive to white matter changes and, as such, are the best predictors of cognitive decline.

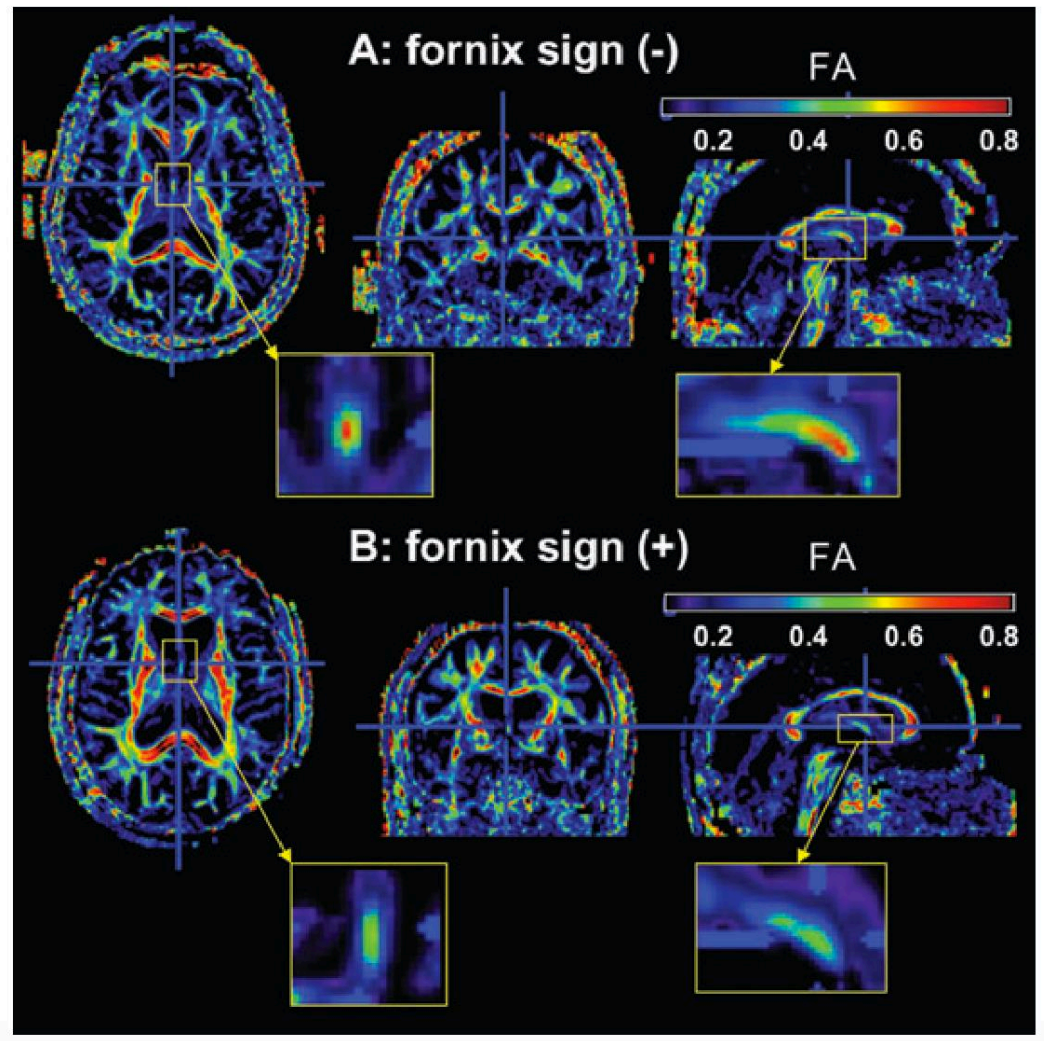

Figure 4. The "fornix sign". The colors on fractional anisotropy (FA) maps in people with white matter degeneration indicate decreased FA in the fornix, one of the early signs of cognitive decline. (A) FA map of a healthy 80-year-old woman without a fornix sign (FA 0.6-0.8). (B) FA map of an 80-year-old woman with Alzheimer's disease with the fornix sign $(\mathrm{FA}<0.5)$. Reproduced with permission from Oishi et al., 2012.

\subsection{The fornix in Alzheimer's Disease}

Alzheimer's Disease (AD) is a progressive neurodegenerative disease marked by significant mnemonic impairment, in addition to other cognitive, affective, and behavioral deficits. The disease is characterized by the presence of beta-amyloid plaques and neurofibrillary tangles in the brain that generally appear first in the medial temporal lobe (MTL) before spreading to the cortex. An early symptom is significant decline in episodic memory performance and hippocampal atrophy is commonly linked to this condition (Apostolova et al., 2012). However, there is also evidence that changes in diffusion metrics in the fornix are evident in $\mathrm{AD}$, discussed below.

Widespread white matter changes are observed in $\mathrm{AD}$, but changes in the fornix are especially interesting since such changes accord with essential limbic pathology and are consistently observed across different samples and methodologies (Oishi \& Lyketsos, 2014). Fornix pathology will necessarily impair cholinergic transmission to the hippocampus. Indeed, it has been known for decades that AD is accompanied by loss of this transmission (Coyle, Price, 
\& Delong, 1983). Like in MCI, AD pathology is associated with decreased FA/increased MD in the fornix (Agosta et al., 2011; Bozoki et al., 2012; Mielke et al., 2012; Mayo, Mazerolle, Ritchie, Fisk, \& Gawryluk, 2017; Tang et al., 2017; Nir et al., 2013; Nowrangi et al., 2013; Kantarci et al., 2017). There is some inconsistency in whether any given study finds a change in FA or MD, however, the fornix is consistently implicated, regardless of the diffusion parameter showing changes. Additionally, fornix diffusivity metrics are consistently linked to worse performance on memory tasks for patients with both MCI and AD (reviewed in Douet \& Chang, 2015), highlighting the specific connection between fornix pathology and memory impairment.

One of the most important findings regarding the fornix is that white matter abnormalities may precede the gray matter degradation in the MTL that is typical of Alzheimer's pathology (Agosta et al., 2011; Fletcher et al., 2013, 2014; Zhuang et al., 2013; reviewed in Douet \& Chang, 2015), and often is present in patients with aMCI before they convert to AD. This has led to the controversial suggestion that early white matter disruption (especially in the fornix) triggers an adaptive response of deposition of amyloid and tau along with deficits in cholinergic transmission (Bartzokis, 2011). The change in cholinergic transmission leads to the behavioral manifestation - memory problems - while the accumulation of amyloid and tau potentially cause the secondary deterioration of hippocampal gray matter. This would explain why traumatic brain injury and cerebro-vascular disease, which are both associated with diffuse axonal injury as well as damage to myelin, are also strong risk factors for AD (Filley \& Fields, 2016). Clinicians are interested in predicting Alzheimer's disease in vivo. Therefore, tracking changes in white matter diffusion properties could be an effective method for projecting future amnestic symptoms and cognitive decline in older adults. Tissue loss and microstructural changes in the fornix have been found to be predictive of conversion from normal cognition to MCI and $\mathrm{AD}$ (Fletcher et al., 2014). In addition, there is some evidence that acetylcholinesterase inhibitors which are commonly prescribed for the treatment of $\mathrm{AD}$, can have a positive effect on myelination (Bartzokis, 2007).

In sum, there is strong evidence that fornix pathology is tightly associated with the development of $\mathrm{AD}$, and tracking this pathology using diffusion imaging can be an effective way to predict cognitive decline and memory impairment in older adults at risk for developing AD.

\subsection{The fornix in schizophrenia, psychosis, and mood disorders}

The diffusion imaging literature on schizophrenia is quite large due to long-standing theories about disrupted circuitry in this disorder (Andreasen, Paradiso, \& O'Leary, 1998). In addition, schizophrenia is often accompanied by wide spread cognitive alterations including changes in relational memory (Jung \& Lee, 2016), which provides a theoretical justification for looking at the fornix in this disorder. While some studies have reported changes in fornix microstructure in schizophrenia, others have not (reviewed by Douet and Chang, 2015; see also (Baumann et al., 2016). However, post-mortem studies of individuals with schizophrenia have not found that the fornix is altered (reviewed by Douet and Chang, 2015) and case reports on humans with fornix damage do not report that they suffer from delusions, thought disorder, or hallucinations. Explanations for inconsistent findings include enlarged ventricles in individuals with schizophrenia (Sayo et al., 2012) which can bias the diffusion metrics (see Box 1) and heterogeneous etiologies in the sample population. Nevertheless, this remains an interesting tract to target in this population, using optimized imaging methods.

A stronger case can be made for the fornix in mood disorders. It has been hypothesized that the fornix plays an important role in the mediation of fear and anxiety (Degroot \& Treit, 
2004) as well as daily stress, as the conduit of glucocorticoids to the hippocampus (Savransky et al., 2017). Alterations to the fornix microstructure may cause affective dysregulation, which is observed in many mood disorders. For example, variations in the microstructural properties of the fornix body have been associated with early trauma and with symptom severity in individuals with panic disorder (Yu, Lee, \& Lee, 2017). Adolescents with bipolar disorder had lower fornix FA compared to age-matched controls, suggesting that alterations in this white matter pathway are present early in the course of the disease (Barnea-Goraly, Chang, Karchemskiy, Howe, \& Reiss, 2009). Another study reported that unmedicated patients with bipolar disorder had reduced fimbria volume compared to medicated patients and controls (Elvsåshagen et al., 2012). A recent pilot study reported that deep brain stimulation of the fornix improved mood in individuals with $\mathrm{AD}$ (Mao et al., 2018). These results corroborate findings in healthy controls showing that individual differences in sub-clinical anxiety scale with fornix microstructure (Modi et al., 2013). Although the findings we listed are a mixed lot of clinical disorders and methods, they hint that the fornix may play a role in affect regulation, which would not be surprising since the subcortical nuclei at the anterior end of the fornix are involved in many essential limbic functions, including reward signaling. Future research should examine whether the fornix is demyelinated or atrophied in stress-related disorders like post-traumatic stress disorder.

\subsection{The fornix in aberrant reward-seeking: eating disorders and substance abuse}

Decisions about when to eat and where to optimally forage for food rely on long-term memories (see Section 4.2). Thus, it is possible that alterations in fornix microstructure account for pathology in eating behavior. Some studies report that in humans, variation in fornix microstructure correlates with body mass index (BMI; Metzler-Baddeley et al., 2013; Xu, Li, Lin, Sinha, \& Potenza, 2013; reviewed in Kullmann, Schweizer, Veit, Fritsche, \& Preissl, 2015). These studies generally show that higher BMI is associated with lower FA, higher MD, or both. In addition to degraded fornix microstructure in those who are overweight or obese, there is a similar pattern in those with eating disorders of food restriction, such as anorexia nervosa (AN) and bulimia nervosa (BN). Several studies have investigated this relationship and found decreased FA values, increased MD values, or both in participants with AN (Kazlouski et al., 2011; Frank, Shott, Hagman, \& Yang, 2013; Monzon, Hay, Foroughi, \& Touyz, 2016; Phillipou et al., 2018) and BN (Kazlouski et al., 2011; Mettler, Shott, Pryor, Yang, \& Frank, 2013). This pattern across participants who are both over- and underweight suggests that the fornix may be integral in circuitry related to eating behaviors. However, many of these studies found microstructural changes in tracts other than the fornix, indicating that very high or low BMI (or perhaps frequent vacillations in body weight related to disordered eating patterns) may lead to widespread white matter changes across the brain that are not constrained to the fornix. This is complimented by findings that indicate no group differences in white matter microstructure between women who have recovered from AN and normal controls (Bang, Rø, \& Endestad, 2018), suggesting that the white matter abnormalities found in patients with AN may be a result of eating disorder pathology rather than a cause.

One review suggests that such white matter degradation in the brain is related to increased inflammation in the body due to poor physical health, which can in turn impact neurons' myelin sheaths (Porter, Leckie, \& Verstynen, 2018). More work is needed to elucidate whether there is a particular role of the fornix in eating behaviors, or if instead having a BMI outside what is considered the normal range is related to nonspecific white matter degradation across the brain. Since abnormal eating behaviors are often related to restriction or bingeing or 
both, there is a component of cognitive control and reward seeking inherently tied to disordered eating. Perhaps it is these behaviors that are tied to the altered fornix microstructure in people who are over- or underweight.

Substance abuse is a classic model of reward seeking gone awry. We recently reviewed the diffusion imaging literature on substance abuse (Hampton, Hanik, \& Olson, 2019) and found that the literature was highly inconsistent, even when restricted to a particular substance like cocaine. The fornix was mentioned as being affected in only a single study of adolescents with alcohol use disorder (Cardenas et al., 2013). We do not think the absence of findings should be taken as truth, however. We found that this literature suffered from many methodological problems such as imaging methods with poor signal-to-noise ratios, few diffusion directions, reliance on whole brain TBSS analyses, and absence of hypotheses that might point towards a specific tract or brain region. Future research should closely examine the fornix, especially in substance use disorders where pleasurable memories may be especially important in driving behavior (e.g. opioids).

\section{At the cutting-edge: deep brain stimulation of the fornix}

There is currently great interest in electrically stimulating the fornix to potentially improve memory in MCI and AD. This idea has its genesis in a now-classic study by Hamani and colleagues, in which the goal was to use deep brain stimulation (DBS) of the hypothalamus to help with weight control in a patient who was morbidly obese (Hamani et al., 2008). DBS functions therapeutically in humans at frequencies between 80 and $185 \mathrm{~Hz}$ and with a stimulation current between 1 and $10 \mathrm{~mA}$ (Vedam-Mai et al., 2012). The effects of DBS on neuronal function can be excitatory or inhibitory, depending on the stimulation site. In Hamani and colleagues' study (2008), they inadvertently stimulated the fornix (due to the proximity of the fornix to the hypothalamus), which caused the patient to recount extremely detailed autobiographical memories during the surgery, as well as leading to increased activity in the hippocampus and parahippocampal cortex. The patient continued to demonstrate increased performance on verbal recognition and spatial memory assessments after three weeks of continuous stimulation (Hamani et al., 2008).

This compelling finding helped launch a small industry of fornix DBS studies. Studies in rats showed that DBS of the fornix can activate the hippocampus (Gondard et al., 2015) and can reset hippocampal theta, promoting optimal memory encoding (Williams \& Givens, 2003). DBS of the fornix in rats also improves performance on hippocampal-dependent spatial memory tasks (Hescham et al., 2013; Zhang, Hu, Wu, Zhang, \& Zhang, 2015). Additionally, it can reverse Alzheimer's-type memory impairments in these rats (Hescham et al., 2013), but does not appear to have an effect on the presence of Alzheimer's-related proteins such as beta-amyloid or tau (Gondard et al. 2015).

The benefits to memory in rats with impairments mimicking Alzheimer's deficits raises the question of whether this would translate to humans. Several studies have revealed optimistic findings: fornix DBS in humans can drive neural activity in the entorhinal cortex and hippocampus to reverse impaired glucose utilization in the temporal and parietal lobes (Laxton et al., 2010) and increase metabolism in the medial temporal lobes (Fontaine et al., 2013). In addition, patients with AD who were receiving DBS to the fornix showed slowed hippocampal atrophy relative to AD controls who did not receive stimulation (Sankar et al., 2015). Case studies have also shown that patients whose memory was declining prior to fornix stimulation stabilized after DBS (Laxton et al., 2010; Fontaine et al., 2013), and that even patients with 
severe AD showed some improvements in mood, memory, and language ability, as reported by caregivers (Mao et al., 2018).

The memory improvements in these studies are modest, and it has been proposed that more robust results would be obtained if studies employed closed-loop stimulation rather than open-loop stimulation, as closed-loop formats allow stimulation to optimally target memoryrelated activity in the brain (Senova, Chaillet, \& Lozano, 2018). Open-loop stimulation refers to the most common type of DBS in which a constant stimulation, at a constant frequency, is applied. In closed-loop protocols, stimulation is done in targeted intervals at specific frequencies that align with brain activity occurring during either encoding or retrieval periods. Another possibility that can be explored is to use rhythmic DBS of the fornix to pace or replace potentially aberrant hippocampal theta rhythms.

Although the benefits of DBS of the fornix on memory in MCI and AD remain inconclusive, there is some evidence that fornix DBS may have an unexpected benefit for epilepsy. Koubeissi and colleagues (2013) found modest benefits of fornix stimulation on memory recall in epilepsy. More robust was the 92 percent decrease in seizure occurrence, suggesting clinical benefits of fornix stimulation beyond memory improvements (Koubeissi, Kahriman, Syed, Miller, \& Durand, 2013).

\section{Conclusions}

Our review of the fornix literature reveals that it plays an essential role in episodic forms of memory across species and tasks. We were surprised to find that the effects of fornix damage on memory are nearly indistinguishable from the deficits observed after focal hippocampal lesions. Thus, memory processes that are considered "hippocampal" can just as easily be viewed as "fornical". Classic linkages and functional divisions in the literature on the hippocampus such as episodic vs. semantic memory, recall vs. recognition, explicit vs. implicit, are mimicked in the literature on the fornix, supporting an older idea that damage to any part of the "extended hippocampal memory system" would cause similar memory deficits (e.g., Warrington \& Weiskrantz, 1982; Aggleton \& Brown, 1999). The mechanistic role of the fornix is, of course, quite different than the computational role of the hippocampus in episodic memory. The fornix is the conduit by which the neurotransmitter acetylcholine-which is crucial for memory encodingis sent from the medial septum/diagonal band of Broca to the hippocampus. In addition, the GABAergic neurons in the septal nuclei generate theta rhythms which are transmitted through the fornix to the hippocampus. In the absence of these external modulators, the hippocampus is radically dysfunctional.

Without an intact fornix, hippocampal neurons do not have a direct pathway to the basal forebrain or diencephalon, although it retains intact communication with medial temporal lobe regions like the entorhinal cortex, amygdala, and retrosplenial cortex (Aggleton, Wright, Rosene, \& Saunders, 2015). It has been suggested that fornix pathology in MCI and AD should lead to a greater reliance on alternative medial temporal lobe pathways, perhaps via the cingulum bundle (Metzler-Baddeley et al., 2012) or uncinate fasciculus. The cingulum bundle, a large limbic tract connecting the parahippocampal cortex, retrospenial cortex, and cingulate cortex to the frontal lobe, does not appear to play an essential role in episodic memory (Bubb, Metzler-Baddeley, \& Aggleton, 2018). Likewise, the uncinate fasciculus, a limbic pathway that connects the anterior temporal lobe and amygdala to the orbitofrontal cortex/ventromedial prefrontal cortex and frontal pole, plays some role in learning and memory (Von Der Heide, Skipper, Klobusicky, \& Olson, 2013; Alm, Rolheiser, Mohamed, \& Olson, 2015; Alm, Rolheiser, \& Olson, 2016), but its 
contribution is modest compared to the fornix, and most likely limited to retrieval functions. Thus, there does not appear to be any alternative fiber tracts to support relational memory and recollection if the fornix is compromised.

The findings in the lesion literature are mirrored in the newer diffusion imaging literature. Microstructural properties of the fornix, especially FA, decrease with advanced age, correlate with age-related memory impairments, and decrease in disease states defined clinically by episodic memory problems (amnestic MCI and AD). In fact, it has been suggested that fornix pathology precedes gray matter degeneration in the hippocampus as well as secondary loss of white matter volume due to neuronal loss (Zhuang et al., 2013; Fletcher et al., 2013). The "fornix sign," a discoloration of the fornix in color-coded FA maps of the fornix, has been used to predict conversion from MCI to AD (Oishi et al., 2012; see Figure 4).

It is increasingly recognized that brain rhythms are essential for normal cognition. A simple way to perturb a brain rhythm is to alter myelination of the connecting fibers. There are many avenues to myelin disruption - exposure to toxic reagents, metabolic problems, inflammation, infection, and the list goes on (Filley \& Fields, 2016). It is possible that myelin disturbances may cause network disruptions that ultimately lead to neuropsychiatric disorders. The DWI literature has linked changes in the fornix to different psychiatric disorders including schizophrenia and psychosis, bipolar disorder, and eating disorders. We note that in all of these cases, the fornix is not selectively altered, but rather is one of many affected white matter tracts. Unlike the episodic memory literature, the psychosis literature is decidedly mixed on whether or not the fornix plays an important role in the pathophysiology of this disease, potentially due to small and heterogeneous sample populations, and difficulties encountered in imaging the fornix. The literature on bipolar disorder is more promising, and the literature on eating disorders is very small but is beginning to show interesting relationships between fornix microstructure and eating behavior. We suggest that future researchers interested in psychosis and/or bipolar disorder should (a) measure episodic memory performance (preferably using a task with relational and spatial processing demands) as well as stress and allostatic load, and correlate these measures with fornix microstructure, rather than clinical diagnosis per se; (b) use optimized imaging methods as described in Box 1.

Our review exposed several gaps in the literature that we detail in Box 2. We note that the human literature on the fornix would benefit by drawing from the rich literature on the rodent fornix. For instance, lesion and DWI studies of humans should use tasks that depend on an intact fornix in rodents and monkeys (see Table 1). Using tasks like reversal learning or trace conditioning in humans would allow for greater cross-species comparison. In addition, delineating the contributions of each MTL subregion has been the primary focus of most memory models in terms of their distinct computational properties (Montaldi \& Mayes, 2010; Norman \& O'Reilly, 2003) and representation-specific processes (Davachi, 2006; Ranganath, 2010). Much controversy surrounds the functional divisions among the MTL gray matter subregions, most notably the hippocampus and MTL cortex including the perirhinal cortex, parahippocampal cortex, and entorhinal cortex. Given the crucial role of the fornix in the multitude of mnemonic processes outlined in this review, integrating this major white matter pathway in these existing theories would generate novel predictions about complex memory capacities expressed as products of an inter-connected circuitry.

In the future, quantitative DWI of the fornix may be able to reliably diagnose $\mathrm{AD}$ and predict conversion from MCI to $\mathrm{AD}$. In addition, imaging of the fornix may be able to provide a differential diagnosis of $\mathrm{AD}$, which is important, given that disorders such as depression can 
have a clinical presentation of memory impairments in the elderly. Apart from imaging the fornix, the effectiveness of treating neuropsychiatric disorders with DBS of the fornix are modest thus far, but have the potential for added benefit with modifications, such as employing closedloop formats. Closed loop stimulation of the fornix could even be used to pace or replace potentially aberrant hippocampal theta rhythms in $\mathrm{AD}$ (see optogenetic study by Giovannetti et al., 2018) and potentially improve mood, not only in $\mathrm{AD}$, but other disorders like unipolar depression (see Mao et al., 2018). There is emerging evidence that scalp EEG can record theta oscillations (Crivelli-Decker, Hsieh, Clarke, \& Ranganath, 2018), opening the door to future research that uses a non-invasive form of brain stimulation, rather than DBS, to modulate theta and. More research is needed to uncover the specific role of the fornix in neuropsychiatric disorders and to discover how best to target this tract for potentially alleviating symptoms or delaying onset of the disorders.

\section{Box 2. Big Questions for Future Research}

1. Does fornix degradation in hippocampal or diencephalic amnesia account for some of the deficits in episodic memory? One of the only studies to look at this found that an individual with developmental amnesia had a partially missing and displaced fornix (Rosenbaum et al., 2014). Given the principle of Wallerian degeneration, it is nearly certain that the fornix is abnormal in this patient population.

2. Is myelin damage in the fornix the catalyst for amyloid and tau deposition, and for later hippocampal cell loss observed in Alzheimer's Disease?

3. How does inflammation affect fornix myelination and what are the downstream effects on brain rhythms such as theta, acetylcholine transmission, and cognitive state?

4. Is the fornix damaged by chronic stress? There is evidence that the hippocampus is acutely sensitive to stress and that oligodendrocytes are also sensitive to stress (McEwen, 2017). This literature has evolved along an axis that is quite separate from the literature on episodic memory; thus, it is unclear how different findings in different literatures relate to one another.

5. Do alterations in fornix microstructure account for pathological eating behavior? The fornix is the conduit by which memories are used to guide decisions; it is part of the interface between the limbic system and action. For instance, decisions about when to eat and where to optimally forage for food rely on a circuit that includes the hippocampus and the fornix. At least one study has reported that in humans, variation in fornix microstructure correlates with body mass index (Metzler-Baddeley et al., 2013). This relationship deserves further attention.

6. How do changes in fornix microstructure relate to episodic memory and other cognitive faculties in young children? Fornix macrostructure is fully developed by age 2, but episodic memory continues to develop for several more years (Ngo, Lin, Newcombe, \& Olson, 2019). Future investigators should examine whether variation in fornix microstructure, more than chronological age, relates to the maturity of memory performance in young children.

7. Is the adult fornix plastic? A ground-breaking study trained both humans and rats on a spatial navigation task. After only two hours of training, there were measurable microstructure changes in the fornix as well as the hippocampus (Hofstetter, Tavor, Tzur Moryosef, \& Assaf, 2013). These findings suggesting that the fornix remains plastic in 
adulthood, that plasticity in this structure occurs rapidly, and that microstructural changes in white matter and gray matter happen in conjunction. This finding deserves further study. For instance, does this finding generalize to other types of learning (see Hofstetter, Friedmann, \& Assaf, 2017)? Is this plasticity maintained in older adults (Vien et al., 2016)?

\section{Acknowledgements}

We would like to thank David Waxler for helpful comments. This work was supported by a National Institute of Health grant to I. Olson [RO1 MH091113]. The content is solely the responsibility of the authors and does not necessarily represent the official views of the National Institute of Mental Health or the National Institutes of Health. 


\section{References}

Abe, K., Inokawa, M., Kashiwagi, A., \& Yanagihara, T. (1998). Amnesia after a discrete basal forebrain lesion. Journal of Neurology Neurosurgery and Psychiatry, 65(1), 126-130. https://doi.org/10.1136/jnnp.65.1.126

Alm, K. H., Rolheiser, T., Mohamed, F. B., \& Olson, I. R. (2015). Fronto-temporal white matter connectivity predicts reversal learning errors. Frontiers in Human Neuroscience, 9(June), 1-11. https://doi.org/10.3389/fnhum.2015.00343

Alm, K. H., Rolheiser, T., \& Olson, I. R. (2016). Inter-individual variation in fronto-temporal connectivity predicts the ability to learn different types of associations. NeuroImage, 132, 213-224. https://doi.org/10.1016/j.neuroimage.2016.02.038

Apostolova, L. G., Green, A. E., Babakchanian, S., Hwang, K. S., Chou, Y.-Y., Woga, A. W., \& Thompson, P. M. (2012). Hippocampal atrophy and ventricular enlargement in normal aging, mild cognitive impairment and Alzheimer's disease. Alzheimer Disease and Associated Disorders, 26(1), 17-27. https://doi.org/10.1097/WAD.0b013e3182163b62.Hippocampal

Aggleton, J. P., \& Brown, M. W. (1999). Episodic memory, amnesia, and the hippocampalanterior thalamic axis. Behavioral and Brain Sciences, 22, 425-489. Retrieved from http://journals.cambridge.org/abstract_S0140525X99002034

Aggleton, J. P., Keith, A. B., Rawlins, J. N. P., Hunt, P. R., \& Sahgal, A. (1992). Removal of the hippocampus and transection of the fornix produce comparable deficits on delayed nonmatching to position by rats. Behavioural Brain Research, 52(1), 61-71. https://doi.org/10.1016/S0166-4328(05)80325-0

Aggleton, J. P., Wright, N. F., Rosene, D. L., \& Saunders, R. C. (2015). Complementary patterns of direct amygdala and hippocampal projections to the macaque prefrontal cortex. Cerebral Cortex, 25(11), 4351-4373. https://doi.org/10.1093/cercor/bhv019

Agosta, F., Pievani, M., Sala, S., Geroldi, C., Galluzzi, S., Frisoni, G. B., \& Filippi, M. (2011). White matter damage in Alzheimer Disease and its relationship to gray matter atrophy. Radiology, 258(3), 853-863. https://doi.org/10.1148/radiol.10101284/-/DC1

Amaral, D., \& Lavenex, P. (2007). Hippocampal Neuroanatomy. In Andersen, P., Morris, R., Amaral, D., Bliss, T. \& O'Keefe, J. (Eds.) The Hippocampus Book (pp. 37-114). New York: Oxford Univ. Press.

Anderson, K. L., Rajagovindan, R., Ghacibeh, G. A., Meador, K. J., \& Ding, M. (2010). Theta oscillations mediate interaction between prefrontal cortex and medial temporal lobe in human memory. Cerebral Cortex, 20, 1604-1612. https://doi.org/10.1093/cercor/bhp223

Andreasen, N. C., Paradiso, S., \& O’Leary, D. S. (1998). "Cognitive Dysmetria” as an Integrative Theory of Schizophrenia. Schizophrenia Bulletin, 24(2), 203-218.

Antonenko, D., Külzow, N., Cesarz, M. E., Schindler, K., Grittner, U., \& Flöel, A. (2016). Hippocampal pathway plasticity is associated with the ability to form novel memories in older adults. Frontiers in Aging Neuroscience, 8(61), 1-8. https://doi.org/10.3389/fnagi.2016.00061

Bach, M., Laun, F. B., Leemans, A., Tax, C. M. W., Biessels, G. J., Stieltjes, B., \& Maier-Hein, K. H. (2014). Methodological considerations on tract-based spatial statistics (TBSS). NeuroImage, 100, 358-369. https://doi.org/10.1016/j.neuroimage.2014.06.021

Bachevalier, J., Parkinson, J. K., \& Mishkin, M. (1985). Visual recognition in monkeys: effects of separate vs. combined transection of fornix and amygdalofugal pathways. Experimental 
Backus, A. R., Schoffelen, J. M., Szebényi, S., Hanslmayr, S., \& Doeller, C. F. (2016).

Hippocampal-prefrontal theta oscillations support memory integration. Current Biology, 26, 450-457. https://doi.org/10.1016/j.cub.2015.12.048

Bang, L., Rø, Ø., \& Endestad, T. (2018). Normal white matter microstructure in women longterm recovered from anorexia nervosa: A diffusion tensor imaging study. International Journal of Eating Disorders, 51(1), 46-52. https://doi.org/10.1002/eat.22802

Barnea-Goraly, N., Change, K. D., Karchemskiy, A., Howe, M., \& Reiss, A. L. (2006). Limbic and corpus callosum aberrations in adolescents with bipolar disorder: A tract-based spatial statistics analysis. Biological Psychiatry, 66(3), 238-244.

Bartzokis, G. (2007). Acetylcholinesterase Inhibitors May Improve Myelin Integrity. Biological Psychiatry, 62(4), 294-301. https://doi.org/10.1016/j.biopsych.2006.08.020

Bartzokis, G. (2011). Alzheimer's disease as homeostatic responses to age-related myelin breakdown. Neurobiology of Aging, 32(8), 1341-1371.

https://doi.org/10.1016/j.neurobiolaging.2009.08.007

Baumann, P. S., Griffa, A., Fournier, M., Golay, P., Ferrari, C., Alameda, L., ... Conus, P. (2016). Impaired fornix-hippocampus integrity is linked to peripheral glutathione peroxidase in early psychosis. Translational Psychiatry, 6(7), e859. https://doi.org/10.1038/tp.2016.117

Bennett, I. J., Huffman, D. J., \& Stark, C. E. L. (2015). Limbic tract integrity contributes to pattern separation performance across the lifespan. Cerebral Cortex, 25, 2988-2999. https://doi.org/10.1093/cercor/bhu093

Bennett, I. J., \& Stark, C. E. L. (2016). Mnemonic discrimination relates to perforant path integrity: An ultra-high resolution diffusion tensor imaging study. Neurobiology of Learning and Memory, 129, 107-112. https://doi.org/10.1016/j.nlm.2015.06.014

Blaker, S. N., Armstrong, D. M., \& Gage, F. H. (1988). Cholinergic neurons within the rat hippocampus: Response to fimbria-fornix transaction. Journal of Comparative Neurology, 272(1), 127-138.

Bozoki, A. C., Korolev, I. O., Davis, N. C., Hoisington, L. A., \& Berger, K. L. (2012). Disruption of limbic white matter pathways in mild cognitive impairment and Alzheimer's disease: A DTI/FDG-PET Study. Human Brain Mapping, 33(8), 1792-1802. https://doi.org/10.1002/hbm.21320

Browning, P. G. F., Gaffan, D., Croxson, P. L., \& Baxter, M. G. (2010). Severe scene learning impairment, but intact recognition memory, after cholinergic depletion of inferotemporal cortex followed by fornix transection. Cerebral Cortex, 20(2), 282-293. https://doi.org/10.1093/cercor/bhp097

Bubb, E. J., Metzler-Baddeley, C., \& Aggleton, J. P. (2018). The cingulum bundle: Anatomy, function, and dysfunction. Neuroscience and Biobehavioral Reviews, 92(January), 104-127. https://doi.org/10.1016/j.neubiorev.2018.05.008

Buckley, M. J., Charles, D. P., Browning, P. G. F., \& Gaffan, D. (2004). Learning and retrieval of concurrently presented spatial discrimination tasks: role of the fornix. Behavioral Neuroscience, 118(1), 138-149. https://doi.org/10.1037/0735-7044.118.1.138

Buckley, M. J., Wilson, C. R. E., \& Gaffan, D. (2008). Fornix transection impairs visuospatial memory acquisition more than retrieval. Behavioral Neuroscience, 122(1), 44-53. https://doi.org/10.1037/0735-7044.122.1.44

Bussey, T. J., Duck, J., Muir, J. L., \& Aggleton, J. P. (2000). Distinct patterns of behavioural 
impairments resulting from fornix transection or neurotoxic lesions of the perirhinal and postrhinal cortices in the rat. Behavioural Brain Research, 111(1-2), 187-202. https://doi.org/10.1016/S0166-4328(00)00155-8

Buzsáki, G., \& Draguhn, A. (2004). Neuroscience Neuronal Oscillations in Cortical Networks. Science, 304(5679), 1926-1938.

Buzsáki, G. (2005). Theta rhythm of navigation: Link between path integration and landmark navigation, episodic and semantic memory. Hippocampus, 15(7), 827-840. https://doi.org/10.1002/hipo.20113

Calabrese, P., Markowitsch, H. J., Harders, A. G., Scholz, M., \& Gehlen, W. (1995). Fornix damage and memory: a case report. Cortex, 31, 555-564. https://doi.org/10.1016/s00109452(13)80066-4

Cardenas, V. A., Greenstein, D., Fouche, J. P., Ferrett, H., Cuzen, N., Stein, D. J., \& Fein, G. (2013). Not lesser but Greater fractional anisotropy in adolescents with alcohol use disorders. NeuroImage: Clinical, 2(1), 804-809. https://doi.org/10.1016/j.nicl.2013.06.002

Cassel, J. C. (1997). The fimbria-fornix/cingular bundle pathways: A review of neurochemical and behavioral approaches using lesions and transplantation techniques. Progress in Neurobiology, 51(6), 663-716.

Catani, M., Howard, R. J., Pajevic, S., \& Jones, D. K. (2002). Virtual in Vivo interactive dissection of white matter fasciculi in the human brain. NeuroImage, 17(1), 77-94. https://doi.org/10.1006/nimg.2002.1136

Cheng, Y. W., Chung, H. W., Chen, C. Y., \& Chou, M. C. (2011). Diffusion tensor imaging with cerebrospinal fluid suppression and signal-to-noise preservation using acquisition combining fluid-attenuated inversion recovery and conventional imaging: Comparison of fiber tracking. European Journal of Radiology, 79(1), 113-117. https://doi.org/10.1016/j.ejrad.2009.12.032

Coyle, J. T., Price, D. L., \& Delong, M. R. (1983). Alzheimer's disease: a disorder of cortical cholinergic innervation. Science, 219(4589), 1184-1190.

Crivelli-Decker, J., Hsieh, L. T., Clarke, A., \& Ranganath, C. (2018). Theta oscillations promote temporal sequence learning. Neurobiology of Learning and Memory, 153(April), 92-103. https://doi.org/10.1016/j.nlm.2018.05.001

Davachi, L. (2006). Item, context and relational episodic encoding in humans. Current Opinion in Neurobiology, 16(6), 693-700. https://doi.org/10.1016/j.conb.2006.10.012

De Bruin, J. P. C., Moita, M. P., De Brabander, H. M., \& Joosten, R. N. J. M. A. (2001). Place and response learning of rats in a Morris water maze: Differential effects of fimbria fornix and medial prefrontal cortex lesions. Neurobiology of Learning and Memory, 75(2), 164 178. https://doi.org/10.1006/nlme.2000.3962

Degroot, A., \& Treit, D. (2004). Anxiety is functionally segregated within the septo-hippocampal system. Brain Research, 1001(1-2), 60-71. https://doi.org/10.1016/j.brainres.2003.10.065

D’Esposito, M., Verfaellie, M., Alexander, M. P., \& Katz, D. I. (1995). Amnesia following traumatic bilateral fornix transection. Neurology, 45(8), 1546-1550. https://doi.org/10.1212/WNL.45.8.1546

Dixon, C. E., Bao, J., Long, D. A., \& Hayes, R. L. (1996). Reduced evoked release of acetylcholine in the rodent hippocampus following traumatic brain injury. Pharmacology Biochemistry and Behavior, 53(3), 679-686. https://doi.org/10.1016/0091-3057(95)02069-1

Douaud, G., Menke, R. A. L., Gass, A., Monsch, A. U., Rao, A., Whitcher, B., ... Smith, S. (2013). Brain Microstructure Reveals Early Abnormalities more than Two Years prior to 
Clinical Progression from Mild Cognitive Impairment to Alzheimer's Disease. Journal of Neuroscience, 33(5), 2147-2155. https://doi.org/10.1523/JNEUROSCI.4437-12.2013

Douet, V., \& Chang, L. (2015). Fornix as an imaging marker for episodic memory deficits in healthy aging and in various neurological disorders. Frontiers in Aging Neuroscience, 7(JAN), 1-19. https://doi.org/10.3389/fnagi.2014.00343

Doxey, C. R., \& Kirwan, B. C. (2015). Structural and functional correlates of behavioral pattern separation in the hippocampus and medial temporal lobe. Hippocampus, 25, 524-533. https://doi.org/10.1002/hipo.22389

Easton, A., Ridley, R. M., Baker, H. F., \& Gaffan, D. (2002). Unilateral lesions of the cholinergic basal forebrain and fornix in one hemisphere and inferior temporal cortex in the opposite hemisphere produce severe learning impairments in rhesus monkeys. Cerebral Cortex, 12, 729-736.

Elvsåshagen, T., Moberget, T., Bøen, E., Boye, B., Englin, N. O. A., Pedersen, P., ... Andersson, S. (2012). Evidence for impaired neocortical synaptic plasticity in bipolar II disorder. Biological Psychiatry, 71(1), 68-74. https://doi.org/10.1016/j.biopsych.2011.09.026

Ennaceur, A., \& Aggleton, J. P. (1997). The effects of neurotoxic lesions of the perirhinal cortex combined to fornix transection on object recognition memory in the rat. Behavioural Brain Research, 88(2), 181-193. https://doi.org/10.1016/S0166-4328(97)02297-3

Ennaceur, A., Neave, N., \& Aggleton, J. P. (1996). Neurotoxic lesions of the perirhinal cortex do not mimic the behavioural effects of fornix transection in the rat. Behavioural Brain Research, 80(1-2), 9-25. https://doi.org/10.1016/0166-4328(96)00006-X

Filley, C. M., \& Fields, R. D. (2016). White matter and cognition: making the connection. Journal of Neurophysiology, 116(5), 2093-2104. https://doi.org/10.1152/jn.00221.2016

Fletcher, E., Raman, M., Huebner, P., Liu, A., Mungas, D., Carmichael, O., \& DeCarli, C. (2013). Loss of fornix white matter volume as a predictor of cognitive impairment in cognitively normal elderly individuals. JAMA Neurology, 70(11), 1389-1395. https://doi.org/10.1001/jamaneurol.2013.3263

Fletcher, E., Carmichael, O., Pasternak, O., Maier-Hein, K. H., \& DeCarli, C. (2014). Early brain loss in circuits affected by Alzheimer's disease is predicted by fornix microstructure but may be independent of gray matter. Frontiers in Aging Neuroscience, 6(MAY), 1-9. https://doi.org/10.3389/fnagi.2014.00106

Fontaine, D., Deudon, A., Lemaire, J. J., Razzouk, M., Viau, P., Darcourt, J., \& Robert, P. (2013). Symptomatic treatment of memory decline in Alzheimer's disease by deep brain stimulation: A feasibility study. Journal of Alzheimer's Disease, 34(1), 315-323. https://doi.org/10.3233/JAD-121579

Frank, G. K. W., Shott, M. E., Hagman, J. O., \& Yang, T. T. (2013). Localized brain volume and white matter integrity alterations in adolescent anorexia nervosa. Journal of the American Academy of Child and Adolescent Psychiatry, 52(10), 1066-1075.e5. https://doi.org/10.1016/j.jaac.2013.07.007

Gaffan, D. (1992). Amnesia for complex naturalistic scenes and for objects following fornix transection in the rhesus monkey. European Journal of Neuroscience, 4(5), 381-388. https://doi.org/10.1111/j.1460-9568.1992.tb00886.x

Gaffan, D. (1994). Dissociated effects of perirhinal cortex ablation, fornix transection and amygdalectomy: evidence for multiple memory systems in the primate temporal lobe. Experimental Brain Research, 99(3), 411-422. https://doi.org/10.1007/BF00228977 Gaffan, D., Parker, A., \& Easton, A. (2001). Dense amnesia in the monkey after transection of 
fornix, amygdala and anterior temporal stem. Neuropsychologia, 39, 51-70. Retrieved from papers2://publication/uuid/81DF149C-626A-423B-A839-8CD483DC7406

Gaffan, E. A., Gaffan, D., \& Hodges, J. R. (1991). Amnesia following damage to the left fornix and to other sites. Brain, 114, 1297-1313.

Ghetti, S., \& Bunge, S. A. (2012). Neural changes underlying the development of episodic memory during middle childhood. Developmental Cognitive Neuroscience, 2(4), 381-395.

Giovannetti, E. A., Poll, S., Justus, D., Kaneko, H., Fuhrmann, F., Steffen, J., ... Fuhrmann, M. (2018). Restoring memory by optogenetic synchronization of hippocampal oscillations in an Alzheimer's disease mouse model. BioRxiv, 363820. https://doi.org/10.1101/363820

Godsil, B. P., Kiss, J. P., Spedding, M., \& Jay, T. M. (2013). The hippocampal-prefrontal pathway: The weak link in psychiatric disorders? European Neuropsychopharmacology, 23(10), 1165-1181. https://doi.org/10.1016/j.euroneuro.2012.10.018

Gondard, E., Chau, H. N., Mann, A., Tierney, T. S., Hamani, C., Kalia, S. K., \& Lozano, A. M. (2015). Rapid modulation of protein expression in the rat hippocampus following deep brain stimulation of the fornix. Brain Stimulation, 8, 1058-1064. https://doi.org/10.1016/j.brs.2015.07.044

Graham, K. S., Barense, M. D., \& Lee, A. C. H. (2010). Going beyond LTM in the MTL: A synthesis of neuropsychological and neuroimaging findings on the role of the medial temporal lobe in memory and perception. Neuropsychologia, 48(4), 831-853. https://doi.org/10.1016/j.neuropsychologia.2010.01.001

Gudden, H. (1896). Klinische und anatomische Beiträge zur Kenntniss der multiplen Alkoholneuritis nebst Bemerkungen über die Regenerationsvorgänge im peripheren Nervensystem. Archiv Für Psychiatrie Und Nervenkrankheiten, 28(3), 643-741. https://doi.org/10.1007/BF01988269

Gunbey, H. P., Ercan, K., Findikoglu, A. S., Bulut, H. T., Karaoglanoglu, M., \& Arslan, H. (2014). The limbic degradation of aging brain: A quantitative analysis with diffusion tensor imaging. The Scientific World Journal, 2014, 1-7. https://doi.org/10.1155/2014/196513

Gyebnár, G., Szabó, Á., Sirály, E., Fodor, Z., Sákovics, A., Salacz, P., ... Csukly, G. (2018). What can DTI tell about early cognitive impairment? - Differentiation between MCI subtypes and healthy controls by diffusion tensor imaging. Psychiatry Research Neuroimaging, 272(October 2017), 46-57.

Hamani, C., McAndrews, M. P., Cohn, M., Oh, M., Zumsteg, D., Shapiro, C. M., ... Lozano, A. M. (2008). Memory enhancement induced by hypothalamic/fornix deep brain stimulation. Annals of Neurology, 63, 119-123. https://doi.org/10.1002/ana.21295

Hampton, W. H., Hanik, I. M., \& Olson, I. R. (2019). Substance abuse and white matter: Findings, limitations, and future of diffusion tensor imaging research. Drug and Alcohol Dependence, 197(January), 288-298. https://doi.org/10.1016/j.drugalcdep.2019.02.005

Hanslmayr, S., Staresina, B. P., \& Bowman, H. (2016). Oscillations and Episodic Memory: Addressing the Synchronization/Desynchronization Conundrum. Trends in Neurosciences, 39(1), 16-25. https://doi.org/10.1016/j.tins.2015.11.004

Hasselmo, M.E. (1999). Neuromodulation: acetylcholine and memory consolidation. Trends in Cognitive Sciences, 101(9), 162-183.

Hasselmo, M.E., \& Stern, C. E. (2014). Theta rhythm and the encoding and retrieval of space and time. NeuroImage, 85(0 2), 656-666. https://doi.org/10.1016/j.neuroimage.2013.06.022

Hattori, T., Yuasa, T., Aoki, S., Sato, R., Sawaura, H., Mori, T., \& Mizusawa, H. (2011). Altered microstructure in corticospinal tract in idiopathic normal pressure hydrocephalus: 
Comparison with Alzheimer disease and Parkinson disease with dementia. American Journal of Neuroradiology, 32(9), 1681-1687. https://doi.org/10.3174/ajnr.A2570

Heath, R.G. (1964). Pleasure response of human subjects to direct stimulation of the brain: Physiologic and psychodynamic considerations. The role of pleasure in behavior. New York: Harper \& Row, 219-243.

Heath, R. G. (1972). Pleasure and brain activity in man: Deep and surface electroencephalograms during orgasm. Journal of Nervous and Mental Disease. https://doi.org/10.1097/00005053-197201000-00002

Hebben, N., Corkin, S., Eichenbaum, H., \& Shedlack, K. (1985). Diminished ability to interpret and report internal states after bilateral medial temporal resection: case H.M. Behavioral Neuroscience, 99(6), 1031-1039. Retrieved from http://www.ncbi.nlm.nih.gov/pubmed/3843537

Hescham, S., Lim, L. W., Jahanshahi, A., Steinbusch, H. W. M., Prickaerts, J., Blokland, A., \& Temel, Y. (2013). Deep brain stimulation of the forniceal area enhances memory functions in experimental dementia: The role of stimulation parameters. Brain Stimulation, 6, 72-77. https://doi.org/10.1016/j.brs.2012.01.008

Higgs, S., Williamson, A. C., Rotshtein, P., \& Humphreys, G. W. (2008). Sensory-Specific Satiety Is Intact in Amnesics Who Eat Multiple. Psychological Science, 19(7), 623-628.

Hirsh, R., \& Segal, M. (1972). Complete transection of the fornix and reversal of position habit in the rat. Physiology and Behavior, 8(6), 1051-1054. https://doi.org/10.1016/00319384(72)90196-5

Hodges, J. R., \& Carpenter, K. (1991). Anterograde amnesia with fornix damage following removal of IIIrd ventricle colloid cyst. Journal of Neurology Neurosurgery and Psychiatry, 54, 633-638. https://doi.org/10.1136/jnnp.54.7.633

Hodgetts, C. J., Postans, M., Warne, N., Varnava, A., Lawrence, A. D., \& Graham, K. S. (2017). Distinct contributions of the fornix and inferior longitudinal fasciculus to episodic and semantic autobiographical memory. Cortex, 94, 1-14. https://doi.org/10.1016/j.cortex.2017.05.010

Hodgetts, C. J., Stefani, M., Williams, A. N., Kolarik, B. S., Yonelinas, A. P., Ekstrom, A. D., ... Graham, K. S. (2018). The role of the fornix in human navigational learning. bioRxiv. https://doi.org/https://doi.org/10.1101/391888

Hofstetter, S., Tavor, I., Tzur Moryosef, S., \& Assaf, Y. (2013). Short-term learning induces white matter plasticity in the fornix. Journal of Neuroscience, 33(31), 12844-12850. https://doi.org/10.1523/jneurosci.4520-12.2013

Hofstetter, Shir, Friedmann, N., \& Assaf, Y. (2017). Rapid language-related plasticity: microstructural changes in the cortex after a short session of new word learning. Brain Structure and Function, 222(3), 1231-1241. https://doi.org/10.1007/s00429-016-1273-2

Hsieh, L. T., \& Ranganath, C. (2014). Frontal midline theta oscillations during working memory maintenance and episodic encoding and retrieval. Neurolmage, 85, 721-729. https://doi.org/10.1016/j.neuroimage.2013.08.003

Huang, H. (2010). Delineating neural structures of developmental human brains with diffusion tensor imaging. TheScientificWorldJournal, 10, 135-144. https://doi.org/10.1100/tsw.2010.21

Jang, S. H., Cho, S. H., \& Chang, M. C. (2011). Age-related degeneration of the fornix in the human brain: A diffusion tensor imaging study. International Journal of Neuroscience, 121, 94-100. https://doi.org/10.3109/00207454.2010.531894 
Ji, J., \& Maren, S. (2008). Lesions of the entorhinal cortex or fornix disrupt the contextdependence of fear extinction in rats. Behavioural Brain Research, 194(2), 201-206. https://doi.org/10.1016/j.bbr.2008.07.011

Jung, W., \& Lee, S.-H. (2016). Memory deficit in patients with schizophrenia and posttraumatic stress disorder: relational vs item-specific memory. Neuropsychiatric Disease and Treatment, 12, 1157-1166. https://doi.org/10.2147/NDT.S104384

Kantarci, K., Murray, M. E., Schwarz, C. G., Reid, R. I., Przybelski, S. A., Lesnick, T., ... Dickson, D. W. (2017). White-matter integrity on DTI and the pathologic staging of Alzheimer's disease. Neurobiology of Aging, 56, 172-179. https://doi.org/10.1016/j.neurobiolaging.2017.04.024

Kantarci, K., Schwarz, C. G., Reid, R. I., Przybelski, S. A., Lesnick, T. G., Zuk, S. M., ... Jack, C. R. (2014). White matter integrity determined with diffusion tensor imaging in older adults without dementia: Influence of amyloid load and neurodegeneration. JAMA Neurology, 71(12), 1547-1554. https://doi.org/10.1001/jamaneurol.2014.1482

Kantarci, K., Senjem, M. L., Avula, R., Zhang, B., Samikoglu, a R., Weigand, S. D., ... Jack, C. R. (2011). Diffusion tensor imaging and cognitive function in older adults with no dementia.1. Kantarci K, Senjem ML, Avula R, et al. Diffusion tensor imaging and cognitive function in older adults with no dementia. Neurology. 2011;77(1):26-34. doi:10.1212/WNL.0b013. Neurology, 77, 26-34. https://doi.org/10.1212/WNL.0b013e31822313dc

Kaufmann, L. K., Baur, V., Hänggi, J., Jäncke, L., Piccirelli, M., Kollias, S., ... Milos, G. (2017). Fornix Under Water? Ventricular Enlargement Biases Forniceal Diffusion Magnetic Resonance Imaging Indices in Anorexia Nervosa. Biological Psychiatry: Cognitive Neuroscience and Neuroimaging, 2(5), 430-437. https://doi.org/10.1016/j.bpsc.2017.03.014

Kazlouski, D., Rollin, M. D. H., Tregellas, J., Shott, M. E., Jappe, L. M., Hagman, J. O., ... Frank, G. K. W. (2011). Altered fimbria-fornix white matter integrity in anorexia nervosa predicts harm avoidance. Psychiatry Research - Neuroimaging, 192(2), 109-116. https://doi.org/10.1016/j.pscychresns.2010.12.006

Khakpai, F., Nasehi, M., Haeri-Rohani, A., Eidi, A., \& Zarrindast, M. R. (2013). Septohippocampo-septal loop and memory formation. Basic and Clinical Neuroscience, 4(1), 523.

Klimesch, W., Doppelmayr, D., Russegger, H., \& Pachinger, T. (1996). Theta band power in human scalp EEG and encoding of new information. Neuroreport, 7, 1235-1240. https://doi.org/10.1016/S0167-8760(96)00057-8

Korematsu, K., Hori, T., Morioka, M., \& Kuratsu, J. ichi. (2010). Memory impairment due to a small unilateral infarction of the fornix. Clinical Neurology and Neurosurgery, 112(2), 164166. https://doi.org/10.1016/j.clineuro.2009.10.016

Koubeissi, M. Z., Kahriman, E., Syed, T. U., Miller, J., \& Durand, D. M. (2013). Low-frequency electrical stimulation of a fiber tract in temporal lobe epilepsy. Annals of Neurology, 74, 223-231. https://doi.org/10.1002/ana.23915

Kullmann, S., Schweizer, F., Veit, R., Fritsche, A., \& Preissl, H. (2015). Compromised white matter integrity in obesity. Obesity Reviews. https://doi.org/10.1111/obr.12248

Kwok, S. C., \& Buckley, M. J. (2006). Fornix transection impairs exploration but not locomotion in ambulatory macaque monkeys. Hippocampus, 16, 655-663. https://doi.org/10.1002/hipo

Kwok, S. C., \& Buckley, M. J. (2009). Fornix transected macaques make fewer perseverative errors than controls during the early stages of learning conditional visuospatial 
discriminations. Behavioural Brain Research, 205(1), 207-213. https://doi.org/10.1016/j.bbr.2009.08.016

Kwok, S. C., \& Buckley, M. J. (2010). Long-term visuospatial retention unaffected by fornix transection. Hippocampus, 20(8), 889-893. https://doi.org/10.1002/hipo.20733

Kwok, S. C., Mitchell, A. S., \& Buckley, M. J. (2015). Adaptability to changes in temporal structure is fornix-dependent. Learning and Memory, 22(8), 354-359. https://doi.org/10.1101/lm.038851.115

Laxton, A. W., Tang-Wai, D. F., McAndrews, M. P., Zumsteg, D., Wennberg, R., Keren, R., ... Lozano, A. M. (2010). A phase I trial of deep brain stimulation of memory circuits in Alzheimer's disease. Annals of Neurology, 68, 521-534. https://doi.org/10.1002/ana.22089

Lebel, C., Walker, L., Leemans, A., Phillips, L., \& Beaulieu, C. (2008). Microstructural maturation of the human brain from childhood to adulthood. NeuroImage, 40(3), 10441055. https://doi.org/10.1016/j.neuroimage.2007.12.053

Lebel, C., Gee, M., Camicioli, R., Wieler, M., Martin, W., Beaulieu, C. (2012). Diffusion tensor imaging of white matter tract evolution over the lifespan. NeuroImage, 60(1), 340-352.

Lee, A. C. H., Buckley, M. J., Pegman, S. J., Spiers, H., Scahill, V. L., Gaffan, D., ... Graham, K. S. (2005). Specialization in the medial temporal lobe for processing of objects and scenes. Hippocampus, 15(6), 782-797. https://doi.org/10.1002/hipo.20101

Lega, B. C., Jacobs, J., \& Kahana, M. (2012). Human hippocampal theta oscillations and the formation of episodic memories. Hippocampus, 22, 748-761. https://doi.org/10.1002/hipo.20937

Lipponen, A., Woldemichael, B. T., Gurevicius, K., \& Tanila, H. (2012). Artificial theta stimulation impairs encoding of contextual fear memory. PLoS ONE, 7(11), e48506.

Lisman, J. E., \& Grace, A. A. (2005). The hippocampal-VTA loop: Controlling the entry of information into long-term memory. Neuron, 46(5), 703-713. https://doi.org/10.1016/j.neuron.2005.05.002

Mao, Z. Q., Wang, X., Xu, X., Cui, Z. Q., Pan, L. S., Ning, X. J., .. Yu, X. G. (2018). Partial improvement in performance of patients with severe Alzheimer's disease at an early stage of fornix deep brain stimulation. Neural Regeneration Research, 13(12), 2164-2172. https://doi.org/10.4103/1673-5374.241468

Maren, S., \& Fanselow, M. S. (1997). Electrolytic lesions of the fimbria/fornix, dorsal hippocampus, or entorhinal cortex produce anterograde deficits in contextual fear conditioning in rats. Neurobiology of Learning and Memory, 67(2), 142-149. https://doi.org/10.1006/nlme.1996.3752

Markowska, A. L., Olton, D. S., Murray, E. A., \& Gaffan, D. (1989). A comparative analysis of the role of fornix and cingulate cortex in memory: rats. Experimental Brain Research, 74, $187-201$.

Mayo, C. D., Mazerolle, E. L., Ritchie, L., Fisk, J. D., \& Gawryluk, J. R. (2017). Longitudinal changes in microstructural white matter metrics in Alzheimer's disease. NeuroImage: Clinical, 13, 330-338. https://doi.org/10.1016/j.nicl.2016.12.012

McEwen, B. S. (2017). Neurobiological and Systemic Effects of Chronic Stress. Chronic Stress, 1, 247054701769232. https://doi.org/10.1177/2470547017692328

McMackin, D., Cockburn, J., Anslow, P., \& Gaffan, D. (1995). Correlation of fornix damage with memory impairment in six cases of colloid cyst removal. Acta Neurochirurgica, 135(1-2), 12-18. https://doi.org/10.1007/BF02307408

Mettler, L. N., Shott, M. E., Pryor, T., Yang, T. T., \& Frank, G. K. W. (2013). White matter 
integrity is reduced in bulimia nervosa. International Journal of Eating Disorders, 46(3), 264-273. https://doi.org/10.1002/eat.22083

Metzler-Baddeley, C., Baddeley, R. J., Jones, D. K., Aggleton, J. P., \& O’Sullivan, M. J. (2013). Individual Differences in Fornix Microstructure and Body Mass Index. PLoS ONE, 8(3), 18. https://doi.org/10.1371/journal.pone.0059849

Metzler-Baddeley, C., Hunt, S., Jones, D.K., Leemans, A., Aggleton, J.P., O'Sullivan, M.J. (2012). Temporal association tracts and the breakdown of episodic memory in mild cognitive impairment. Neurology, 79, 2233-2240.

Metzler-Baddeley, C., Jones, D., Aggleton, J., \& O'Sullivan, M. (2011a). The fornix in ageing and memory decline: a diffusion MRI tractography study C. Journal of Neurology, 258(S18). https://doi.org/10.2174/97816080500171080101

Metzler-Baddeley, C., O’Sullivan, M. J., Belaroussi, B., Aggleton, J. P., \& Jones, D. K. (2011b). Frontotemporal Connections in Episodic Memory and Aging: A Diffusion MRI Tractography Study. Journal of Neuroscience, 31(37), 13236-13245. https://doi.org/10.1523/jneurosci.2317-11.2011

Mielke, M. M., Okonkwo, O. C., Oishi, K., Mori, S., Tighe, S., Miller, M. I., ... Lyketsos, C. G. (2012). Fornix integrity and hippocampal volume predict memory decline and progression to Alzheimer's disease. Alzheimer's and Dementia, 8(2), 105-113. https://doi.org/10.1016/j.jalz.2011.05.2416

Milner, B., \& Scoville, W. B. (1957). Loss of recent memory after bilateral hippocampal lesions. Journal of Neurology, Neurosurgery and Psychiatry, 20(11), 11. https://doi.org/10.1136/jnnp-2015-311092

Modi, S., Trivedi, R., Singh, K., Kumar, P., Rathore, R., Tripathy, R. P., \& Khushu, S (2013). Individual differences in trait anxiety are associated with white matter tract integrity in fornix and uncinate fasciculus: Preliminary evidence from a DTI based tractography study. Behavioral Brain Research, 238, 188-192.

Montaldi, D., \& Mayes, A. R. (2010). The role of recollection and familiarity in the functional differentiation of the medial temporal lobes. Hippocampus, 20(11), 1291-1314. https://doi.org/10.1002/hipo.20853

Monzon, B. M., Hay, P., Foroughi, N., \& Touyz, S. (2016). White matter alterations in anorexia nervosa: A systematic review of diffusion tensor imaging studies. World Journal of Psychiatry, 6(1), 177. https://doi.org/10.5498/wjp.v6.i1.177

Moudgil, S. S., Azzouz, M., Al-Azzaz, A., Haut, M., \& Gutmann, L. (2000). Amnesia due to fornix infarction. Stroke, 31, 1418-1419. https://doi.org/10.1161/01.str.31.6.1418

Moseley, M. (2002). Diffusion tensor imaging and aging - A review. NMR in Biomedicine, 15(78), 553-560. https://doi.org/10.1002/nbm.785

Muir, J. L. (1997). Acetylcholine, aging, and Alzheimer's disease. Pharmacology Biochemistry and Behavior, 56(4), 687-696. https://doi.org/10.1016/S0091-3057(96)00431-5

Murray, E. A., Davidson, M., Gaffan, D., Olton, D. S., \& Suomi, S. (1989). Effects of fornix transection and cingulate cortical ablation on spatial memory in rhesus monkeys. Experimental Brain Research, 74(1), 173-186. https://doi.org/10.1007/BF00248291

Nadel, L., Samsonovich, A., Ryan, L., \& Moscovitch, M. (2000). Multiple trace theory of human memory: computational, neuroimaging, and neuropsychological results. Hippocampus, 10(May), 352-368.

Ngo, C. T., Alm, K. H., Metoki, A., Hampton, W., Riggins, T. R., Newcombe, N. S., \& Olson, I. 
R. (2017). White matter structural connectivity and episodic memory in early childhood. Developmental Cognitive Neuroscience, 28, 41-53.

Ngo, C. T., Lin, Y., Newcombe, N. S., \& Olson, I. R. (2019). Building up and wearing down episodic memory: Mnemonic discrimination and relational binding. Journal of Experimental Psychology: General.

Nir, T. M., Jahanshad, N., Villalon-Reina, J. E., Toga, A. W., Jack, C. R., Weiner, M. W., \& Thompson, P. M. (2013). Effectiveness of regional DTI measures in distinguishing Alzheimer's disease, MCI, and normal aging. NeuroImage: Clinical, 3, 180-195. https://doi.org/10.1016/j.nicl.2013.07.006

Norman, K. A., \& Reilly, R. C. O. (2003). Modeling hippocampal and neocortical contributions to recognition memory: A complimentary learning systems approach. Psychological Review, 110(4), 611-646. Retrieved from http://dx.doi.org/10.1037/0033-295X.110.4.611

Nowrangi, M. A., Lyketsos, C. G., Leoutsakos, J. M. S., Oishi, K., Albert, M., Mori, S., \& Mielke, M. M. (2013). Longitudinal, region-specific course of diffusion tensor imaging measures in mild cognitive impairment and Alzheimer's disease. Alzheimer's and Dementia, 9(5), 519-528. https://doi.org/10.1016/j.jalz.2012.05.2186

Oishi, K., \& Lyketsos, C. G. (2014). Alzheimer's disease and the fornix. Frontiers in Aging Neuroscience, 6(SEP), 1-9. https://doi.org/10.3389/fnagi.2014.00241

Oishi, K., Mielke, M. M., Albert, M., Lyketsos, C. G., \& Mori, S. (2012). The fornix sign: A potential sign for alzheimer's disease based on diffusion tensor imaging. Journal of Neuroimaging, 22(4), 365-374. https://doi.org/10.1111/j.1552-6569.2011.00633.x

O'Keefe, J., Nadel, L., Keightley, S., \& Kill, D. (1975). Lesions selectively abolish place learning in the rat. Experimental Neurology, 48, 152-166.

Olds, J., \& Milner, P. (1954). Positive reinforcement produced by electrical stimulation of septal area and other regions of rat brain. The Journal of Comparative and Physiological Psychology. 47(6), 419-427.

Oswald, B. B., Maddox, S. A., \& Powell, D. A. (2007). Impairments in trace EB conditioning by knife-cut lesions to the fornix in rabbits: Reversal by galantamine. Neurobiology of Learning and Memory, 88(3), 369-380. https://doi.org/10.1016/j.nlm.2007.05.005

Pagani, J. H., Zhao, M., Cui, Z., Williams Avram, S. K., Caruana, D. A., Dudek, S. M., \& Young, W. S. (2015). Role of the vasopressin $1 \mathrm{~b}$ receptor in rodent aggressive behavior and synaptic plasticity in hippocampal area CA2. Molecular Psychiatry, 20(4), 490-499. https://doi.org/10.1038/mp.2014.47

Parent, M. A., Wang, L., Su, J., Netoff, T., \& Yuan, L. L. (2010). Identification of the hippocampal input to medial prefrontal cortex in vitro. Cerebral Cortex, 20(2), 393-403. https://doi.org/10.1093/cercor/bhp108

Park, S. A., Hahn, J. H., Kim, J. I., Na, D. L., \& Huh, K. (2000). Memory deficits after bilateral anterior fornix infarction. Neurology, 54(6), 1379-1382. https://doi.org/10.1212/wnl.54.6.1379

Parker, A., \& Gaffan, D. (1997). Madary body lesions in monkeys impair object-in-place memory: functional unity of the fornix-madary system. Journal of Cognitive Neuroscience, $94,512-521$.

Pasternak, O., Sochen, N., Gur, Y., Intrator, N., \& Assaf, Y. (2009). Free water elimination and mapping from diffusion MRI. Magnetic Resonance in Medicine, 62(3), 717-730. https://doi.org/10.1002/mrm.22055

Pelletier, A., Periot, O., Dilharreguy, B., Hiba, B., Bordessoules, M., Pérès, K., ... Catheline, G. 
(2013). Structural hippocampal network alterations during healthy aging: a multi-modal MRI study. Frontiers in Aging Neuroscience, 5(84), 1-10. https://doi.org/10.3389/fnagi.2013.00084

Phillipou, A., Carruthers, S. P., Di Biase, M. A., Zalesky, A., Abel, L. A., Castle, D. J., ... Rossell, S. L. (2018). White matter microstructure in anorexia nervosa. Human Brain Mapping. https://doi.org/10.1002/hbm.24279

Phillips, R., \& LeDoux, J. E., (1992). Differential contribution of amygdala and hippocampus to cued and contextual fear conditioning. Behavioral Neuroscience, 106(2), 274-285. Retrieved from http://psycnet.apa.org/journals/bne/106/2/274.html

Poreh, A., Winocur, G., Moscovitch, M., Backon, M., Goshen, E., Ram, Z., \& Feldman, Z. (2006). Anterograde and retrograde amnesia in a person with bilateral fornix lesions following removal of a colloid cyst. Neuropsychologia, 44, 2241-2248. https://doi.org/10.1016/j.neuropsychologia.2006.05.020

Porter, A., Leckie, R., \& Verstynen, T. (2018). White matter pathways as both a target and mediator of health behaviors. Annals of the New York Academy of Sciences, 71-88. https://doi.org/10.1111/nyas. 13708

Postans, M., Hodgetts, C. J., Mundy, M. E., Jones, D. K., Lawrence, A. D., \& Graham, K. S. (2014). Interindividual Variation in Fornix Microstructure and Macrostructure Is Related to Visual Discrimination Accuracy for Scenes But Not Faces. Journal of Neuroscience, 34(36), 12121-12126. https://doi.org/10.1523/JNEUROSCI.0026-14.2014

Ranganath, C. (2010). A unified framework for the functional organization of the medial temporal lobes and the phenomenology of episodic memory. Hippocampus, 20(11), $1263-$ 1290. https://doi.org/10.1002/hipo.20852

Rawlins, J. N. P., Feldon, J., \& Gray, J. A. (1979). Septo-hippocampal connections and the hippocampal theta rhythm. Experimental Brain Research, 37(1), 49-63. https://doi.org/10.1007/BF01474253

Ray, N. J., Metzler-Baddeley, C., Khondoker, M. R., Grothe, M. J., Teipel, S., Wright, P., ... O'Sullivan, M. J. (2015). Cholinergic basal forebrain structure influences the reconfiguration of white matter connections to support residual memory in mild cognitive impairment. Journal of Neuroscience, 35(2), 739-747. https://doi.org/10.1523/jneurosci.3617-14.2015

Rémy, F., Vayssière, N., Saint-Aubert, L., Barbeau, E., \& Pariente, J. (2015). White matter disruption at the prodromal stage of Alzheimer's disease: Relationships with hippocampal atrophy and episodic memory performance. NeuroImage: Clinical, 7, 482-492. https://doi.org/10.1016/j.nicl.2015.01.014

Reynolds, J. E., Grohs, M. N., Dewey, D., \& Lebel, C. (2019). Global and regional white matter development in early childhood. BioRxiv. [Preprint] https://doi.org/10.1101/524785

Rosenbaum, R. S., Gao, F., Honjo, K., Raybaud, C., Olsen, R. K., Palombo, D. J., ... Black, S. E. (2014). Congenital absence of the mammillary bodies: A novel finding in a well-studied case of developmental amnesia. Neuropsychologia, 65, 82-87. https://doi.org/10.1016/j.neuropsychologia.2014.09.047

Rudebeck, S. R., Scholz, J., Millington, R., Rohenkohl, G., Johansen-Berg, H., \& Lee, A. C. H. (2009). Fornix microstructure correlates with recollection but not familiarity memory. Journal of Neuroscience, 29(47), 14987-14992. https://doi.org/10.1523/jneurosci.470709.2009

Sankar, T., Chakravarty, M. M., Bescos, A., Lara, M., Obuchi, T., Laxton, A. W., ... Lozano, A. 
M. (2015). Deep brain stimulation influences brain structure in Alzheimer's disease. Brain Stimulation, 8(3), 645-654. https://doi.org/10.1016/j.brs.2014.11.020.Deep

Sara, S. J., Dyon-Laurent, C., Guibert, B., \& Leviel, V. (2004). Noradrenergic hyperactivity after partial fornix section: role in cholinergic dependent memory performance. Experimental Brain Research, 89(1), 125-132. https://doi.org/10.1007/bf00229009

Savransky, A., Chiappelli, J., Rowland, L. M., Wisner, K., Shukla, D. K., Kochunov, O., Hong, L. E. (2017). Fornix structural connectivity and allostatic load: Empirical evidence from schizophrenia patients and healthy controls. Psychosomatic Medicine, 79(7), 770-776.

Sayo, A., Jennings, R. G., \& Van Horn, J. D. (2012). Study factors influencing ventricular enlargement in schizophrenia: a 20 year follow-up meta-analysis. NeuroImage, 59(1), 154167. https://doi.org/10.1038/mp.2011.182.doi

Senova, S., Chaillet, A., \& Lozano, A. M. (2018). Fornical closed-loop stimulation for Alzheimer's disease. Trends in Neurosciences, 41(7), 418-428. https://doi.org/10.1016/j.tins.2018.03.015

Squire, L. R., Clark, R. E., \& Knowlton, B. J. (2001). Retrograde amnesia. Hippocampus, 11(1), 50-55. https://doi.org/10.1002/1098-1063(2001)11:1<50::AID-HIPO1019>3.0.CO;2-G

Stadlbauer, A., Salomonowitz, E., Strunk, G., Hammen, T., \& Ganslandt, O. (2008). Quantitative diffusion tensor fiber tracking of age-related changes in the limbic system. European Radiology, 18, 130-137. https://doi.org/10.1007/s00330-007-0733-8

Staudigl, T., \& Hanslmayr, S. (2013). Theta oscillations at encoding mediate the contextdependent nature of human episodic memory. Current Biology, 23(12), 1101-1106. https://doi.org/10.1016/j.cub.2013.04.074

Steel, A., Thomas, C., Trefler, A., Chen, G., \& Baker, C. I. (2019). Finding the baby in the bath water - evidence for task-specific changes in resting state functional connectivity evoked by training. NeuroImage, 188, 524-538. https://doi.org/10.1016/j.neuroimage.2018.12.038

Sullivan, E. V., Rohlfing, T., \& Pfefferbaum, A. (2010). Quantitative fiber tracking of lateral and interhemispheric white matter systems in normal aging: Relations to timed performance. Neurobiology of Aging, 31, 464-481. https://doi.org/10.1016/j.neurobiolaging.2008.04.007

Sweeney, P., \& Yang, Y. (2015). An excitatory ventral hippocampus to lateral septum circuit that suppresses feeding. Nature Communications, 6, 1-11. https://doi.org/10.1038/ncomms 10188

Tang, S. X., Dai, J. P., Feng, Q. L., Duan, S., \& Shan, B. C. (2017). Diffusion characteristics of the fornix in patients with Alzheimer's disease. Psychiatry Research - Neuroimaging, 265(May 2016), 72-76. https://doi.org/10.1016/j.pscychresns.2016.09.012

Tort, A. B. L., Komorowski, R. W., Manns, J. R., Kopell, N. J., \& Eichenbaum, H. (2009). Theta-gamma coupling increases during the learning of item-context associations. Proceedings of the National Academy of Sciences, 106(49), 20942-20947. https://doi.org/10.1073/pnas.0911331106

Trouche, S., Koren, V., Doig, N.M., Ellender, T.J., El-Gaby, M., Lopes-dos-Santos, V., Reeve, H.M., Perestenko, P.V. Garas, F.N., Magill, P.J, Sharott, A., Dupret, D. (2019). A hippocampus-accumbens tripartite neuronal motif guides appetitive memory in space. Cell, 176(6), 1393-1406.

Tsivilis, D., Vann, S. D., Denby, C., Roberts, N., Mayes, A. R., Montaldi, D., \& Aggleton, J. P. (2008). A disproportionate role for the fornix and mammillary bodies in recall versus recognition memory. Nature Neuroscience, 11(7), 834-842. https://doi.org/10.1038/nn.2149

Valji, A., Priemysheva, A., Hodgetts, C. J., Costigan, A. G., Parker, G. D., Graham, K. S., ... 
Gruber, M. J. (2019). Curious connections: white matter pathways supporting individual differences in epistemic and perceptual curiosity. BioRxiv. https://doi.org/https://doi.org/10.1101/642165

Vedam-Mai, V., Van Battum, E. Y., Kamphuis, W., Feenstra, M. G. P., Denys, D., Reynolds, B. A., ... Hol, E. M. (2012). Deep brain stimulation and the role of astrocytes. Molecular Psychiatry, 17, 124-131. https://doi.org/10.1038/mp.2011.61

Vien, C., Boré, A., Lungu, O., Benali, H., Carrier, J., Fogel, S., \& Doyon, J. (2016). Age-related white-matter correlates of motor sequence learning and consolidation. Neurobiology of Aging, 48, 13-22. https://doi.org/10.1016/j.neurobiolaging.2016.08.006

Von Der Heide, R. J., Skipper, L. M., Klobusicky, E., \& Olson, I. R. (2013). Dissecting the uncinate fasciculus: Disorders, controversies and a hypothesis. Brain, 136(6), 1692-1707. https://doi.org/10.1093/brain/awt094

Walker, J. A., \& Olton, D. S. (1979). Spatial memory deficit following fimbria-fornix lesions: Independent of time for stimulus processing. Physiology and Behavior, 23, 11-15. https://doi.org/10.1016/0031-9384(79)90114-8

Warrington, E. K., \& Weiskrantz, L. (1982). Amnesia: A disconnection syndrome? Neuropsychologia, 20(3), 233-248. https://doi.org/10.1016/0028-3932(82)90099-9

Wendelken, C., Lee, J. K., Pospisil, J., Sastre, M., Ross, J. M., Bunge, S. A., \& Ghetti, S. (2015). White Matter Tracts Connected to the Medial Temporal Lobe Support the Development of Mnemonic Control. Cerebral Cortex, 25, 2574-2583. https://doi.org/10.1093/cercor/bhu059

Whishaw, I. Q., \& Tomie, J. A. (1997). Piloting and dead reckoning dissociated by fimbriafornix lesions in a rat food carrying task. Behavioural Brain Research, 89, 87-97. https://doi.org/10.1016/S0166-4328(97)00068-5

Wiig, K. A., Cooper, L. N., \& Bear, M. F. (1996). Temporally graded retrograde amnesia following separate and combined lesions of the perirhinal cortex and fornix in the rat. Learning and Memory, 3, 313-325. https://doi.org/10.1101/lm.3.4.313

Williams, J. M., \& Givens, B. (2003). Stimulation-induced reset of hippocampal theta in the freely performing rat. Hippocampus, 13(1), 109-116. https://doi.org/10.1002/hipo.10082

Wilson, C. R. E., Baxter, M. G., Easton, A., \& Gaffan, D. (2008). Addition of fornix transection to frontal-temporal disconnection increases the impairment in object-in-place memory in macaque monkeys. European Journal of Neuroscience, 27, 1814-1822. https://doi.org/10.1111/j.1460-9568.2008.06140.x

Wilson, C. R. E., Charles, D. P., Buckley, M. J., \& Gaffan, D. (2007). Fornix transection impairs learning of randomly changing object discriminations. Journal of Neuroscience, 27(47), 12868-12873. https://doi.org/10.1523/jneurosci.3536-07.2007'

Winocur, G., McDonald, R. M., \& Moscovitch, M. (2001). Anterograde and retrograde amnesia in rats with large hippocampal lesions. Hippocampus, 11(1), 18-26. https://doi.org/10.1002/1098-1063(2001)11:1<18::AID-HIPO1016>3.0.CO;2-5

Xu, J., Li, Y., Lin, H., Sinha, R., \& Potenza, M. N. (2013). Body mass index correlates negatively with white matter integrity in the fornix and corpus callosum: a diffusion tensor imaging study. Human Brain Mapping, 34(5), 1044-1052. https://doi.org/10.1002/hbm.21491

Yeh, F.-C., Panesar, S., Fernandes, D., Meola, A., Yoshino, M., Fernandez-Miranda, J. C., ... Verstynen, T. (2018). Population-averaged atlas of the macroscale human structural connectome and its network topology. NeuroImage, 178(April), 57-68. https://doi.org/10.1016/j.neuroimage.2018.05.027 
Yu, J., Lam, C. L. M., \& Lee, T. M. C. (2017). White matter microstructural abnormalities in amnestic mild cognitive impairment: A meta-analysis of whole-brain and ROI-based studies. Neuroscience and Biobehavioral Reviews, 83(October), 405-416. https://doi.org/10.1016/j.neubiorev.2017.10.026

Yu, S. T., Lee, K. S., \& Lee, S. H. (2017). Fornix microalterations associated with early trauma in panic disorder. Journal of Affective Disorders, 220(1), 139-146.

Zahr, N. M., Rohlfing, T., Pfefferbaum, A., \& Sullivan, E. V. (2009). Problem solving, working memory, and motor correlates of association and commissural fiber bundles in normal aging: A quantitative fiber tracking study. NeuroImage, 44(3), 1050-1062. https://doi.org/10.1016/j.neuroimage.2008.09.046

Zhang, C., Hu, W. H., Wu, D. L., Zhang, K., \& Zhang, J. G. (2015). Behavioral effects of deep brain stimulation of the anterior nucleus of thalamus, entorhinal cortex and fornix in a rat model of Alzheimer's disease. Chinese Medical Journal, 128(9), 1190-1195. https://doi.org/10.4103/0366-6999.156114

Zhang, H., Lin, S.-C., \& Nicolelis, M. A. L. (2010). Spatiotemporal coupling between hippocampal acetylcholine release and theta oscillations in vivo. Journal of Neuroscience, 30(40), 13431-13440. https://doi.org/10.1523/jneurosci.1144-10.2010

Zhuang, L., Sachdev, P. S., Trollor, J. N., Kochan, N. A., Reppermund, S., Brodaty, H., \& Wen, W. (2012). Microstructural white matter changes in cognitively normal individuals at risk of amnestic MCI. Neurology, 79, 748-754. https://doi.org/10.1212/WNL.0b013e3182661f4d

Zhuang, L., Sachdev, P. S., Trollor, J. N., Reppermund, S., Kochan, N. A., Brodaty, H., \& Wen, W. (2013). Microstructural white matter changes, not hippocampal atrophy, detect early amnestic mild cognitive impairment. PLOS ONE, 8(3), 1-10. https://doi.org/10.1371/journal.pone.0058887 